\title{
Ultra-Stable FeCo Bifunctional Electrocatalyst on Se-Doped CNTs for Liquid and Flexible All-Solid-State Rechargeable Zn-Air Batteries
}

Hongwei Zhang, ${ }^{\dagger}$ Meiqi Zhao, ${ }^{\dagger}$ Haoran Liu, ${ }^{\dagger}$ Shuangrui Shi, ${ }^{\dagger}$ Zhenhua Wang, ${ }^{\dagger}$ Biao

Zhang, ${ }^{\dagger}$ Lin Song, ${ }^{\dagger}$ Jingzhi Shang, ${ }^{\dagger}$ Yong Yang, ${ }^{\perp}$ Chao Ma ${ }^{\triangleleft}$ Lirong Zheng, ${ }^{\#}$ Yunhu Han, ${ }^{\dagger}, t, \xi, *$ and Wei Huang $\dot{\dagger}, *$

†Frontiers Science Center for Flexible Electronics, Xi'an Institute of Flexible Electronics (IFE) and Xi'an Institute of Biomedical Materials \& Engineering, Northwestern Polytechnical University, Xi'an 710072, China

Key Laboratory for Organic Electronics and Information Displays \& Institute of Advanced Materials (IAM), Nanjing University of Posts and Telecommunications, 9 Wenyuan Road, Nanjing 210023, China

${ }^{\S}$ State Key Laboratory of Structural Chemistry, Fujian Institute of Research on the Structure of Matter, Chinese Academy of Sciences, Fuzhou 350002, China

${ }^{\perp}$ School of Materials Science and Engineering, Northwestern Polytechnical University, Xi'an 710072, China

${ }^{\Delta}$ Department of Chemistry, Tsinghua University, Beijing 100084, China

\#Beijing Synchrotron Radiation Facility, Institute of High Energy Physics, Chinese Academy of Sciences, Beijing 100049, China 


\section{Materials and characterizations}

\section{Chemicals}

$\mathrm{Fe}\left(\mathrm{NO}_{3}\right)_{3} \cdot 9 \mathrm{H}_{2} \mathrm{O}$ (98\%, Adamas), $\mathrm{Co}\left(\mathrm{NO}_{3}\right)_{2} \cdot 6 \mathrm{H}_{2} \mathrm{O}$ (99\%, Adamas), Melamine (99\%, Adamas), Se powder (99.999\%, Metals basis, 200 mesh), Ethanol (AR, Anhydrous, $\geq 99.7 \%$ ), Deionized water.

\section{Preparation of the $\mathrm{Fe} / \mathrm{CNT}$ catalyst}

$2 \mathrm{mmol} \mathrm{Fe}\left(\mathrm{NO}_{3}\right)_{3} \cdot 9 \mathrm{H}_{2} \mathrm{O}$ were dissolved in $10 \mathrm{ml}$ ethanol. Then the solution was sonicated for 10 minutes, and dropped evenly on the quartz plate in the $70{ }^{\circ} \mathrm{C}$ electric heating blast drying oven. The quartz plate was allowed to stand for 20 minutes until the ethanol was completely evaporated and dark yellow crystals remained on it. Then the quartz plate was buckled upside down on a burning boat containing $5 \mathrm{~g}$ melamine, paying attention to gaps. Subsequently, the sample was pyrolyzed at $800^{\circ} \mathrm{C}$ for $3 \mathrm{~h}$ with the heating rate $5{ }^{\circ} \mathrm{C} \min ^{-1}$ in a $\mathrm{N}_{2}$ atmosphere. After the calcination was completed, the carbon nanotubes on the quartz plate were scraped off and collected, and they were recorded as $\mathrm{Fe} / \mathrm{CNT}$.

\section{Preparation of the $\mathrm{Co} / \mathrm{CNT}$ catalyst}

$2 \mathrm{mmol} \mathrm{Co}\left(\mathrm{NO}_{3}\right)_{2} \cdot 6 \mathrm{H}_{2} \mathrm{O}$ were dissolved in $10 \mathrm{ml}$ ethanol. The subsequent process was similar to the Fe/CNT catalyst synthesis method. Finally, we marked the collected powder as $\mathrm{Co} / \mathrm{CNT}$.

\section{Preparation of the Se-CNT catalyst}

The mixture of Industrial multi-walled carbon nanotubes $(35 \mathrm{mg}$ ) and Se powder (20 $\mathrm{mg}$ ) were dispersed in $15 \mathrm{ml}$ deionized water and $15 \mathrm{ml}$ ethanol. The dispersed solution was reacted by solvothermal method at $200{ }^{\circ} \mathrm{C}$ for $20 \mathrm{~h}$. Finally, the product was washed twice with ethanol and then dried and collected. 


\section{Preparation of the FeCo/CNT catalyst}

$2 \mathrm{mmol} \mathrm{Fe}\left(\mathrm{NO}_{3}\right)_{3} \cdot 9 \mathrm{H}_{2} \mathrm{O}$ and $0.2 \mathrm{mmol} \mathrm{Co}\left(\mathrm{NO}_{3}\right)_{2} \cdot 6 \mathrm{H}_{2} \mathrm{O}$ were dissolved in $10 \mathrm{ml}$ ethanol. The subsequent process was similar to the Fe/CNT catalyst synthesis method. Finally, we marked the collected powder as $\mathrm{FeCo} / \mathrm{CNT}$.

\section{Preparation of the FeCo/Se-CNT catalyst}

The mixture of as-obtained $\mathrm{FeCo} / \mathrm{CNT}$ catalyst $(35 \mathrm{mg})$ and Se powder $(20 \mathrm{mg})$ were dispersed in $15 \mathrm{ml}$ deionized water and $15 \mathrm{ml}$ ethanol. The dispersed solution is reacted by solvothermal method at $200{ }^{\circ} \mathrm{C}$ for $20 \mathrm{~h}$. Finally, the product was washed twice with ethanol and then dried and collected.

\section{Characterization}

The phase structure of the sample was characterized by powder X-ray diffractometer (Rigaku RU-200b X-ray powder diffractometer with $\mathrm{Cu} \mathrm{K} \alpha$ radiation $(\lambda$ $=1.5406 \AA$ ), $2^{\circ} \mathrm{min}^{-1}$ ). The morphology, structure and chemical composition of the sample were characterized by the scanning electron microscope (SEM, Hitachi S4800, $30 \mathrm{kV}$ ), transmission electron microscope (TEM, Hitachi H-800 transmission electron microscope), high resolution transmission electron microscope (HR-TEM) and energydispersive spectrum of high-angle ring dark field (HAADF-EDS, JEOL-2100F FETEM with electron acceleration energy of $200 \mathrm{kV}$ ). Raman spectra were conducted by using a Invia reflex Raman microscopy system (RENISHAW). X-ray photoelectron spectrometer (XPS, ULVAC PHI Quantera microscope machine) was further used to analyze the structural information of the sample. Elemental analysis of $\mathrm{Co}, \mathrm{Fe}$ and $\mathrm{Se}$ in the solid samples was detected by an Optima 7300 DV inductively coupled plasma mass spectrometer (ICP-MS). The X-ray absorption find structure spectra (Fe K-edge) were collected at 1W1B station in Beijing Synchrotron Radiation Facility (BSRF). The storage rings of BSRF were operated at $2.5 \mathrm{GeV}$ with an average current of $250 \mathrm{~mA}$. Using Si (111) double-crystal monochromator, the data collections were carried out in 
transmission/fluorescence mode using ionization chamber. All spectra were collected in ambient conditions.

\section{XAFS measurements and analysis details}

X-ray absorption find structure (XAFS) spectra (Ru K-edge) were collected at BL14W1 station in Shanghai Synchrotron Radiation Facility (SSRF). The storage rings of SSRF were operated at $3.5 \mathrm{GeV}$ with a maximum current of $250 \mathrm{~mA}$. Using Si (311) double-crystal monochromator, the data collection was carried out in transmission mode using ionization chamber for $\mathrm{Ru}$ foil, $\mathrm{RuO}_{2}$ and in fluorescence excitation mode using a 7 element Ge detector for Ru1@ $\mathrm{WO}_{\mathrm{x}} / \mathrm{CN}$. All spectra were collected in ambient conditions. The acquired EXAFS data were processed according to the standard procedures using the ATHENA module implemented in the IFEFFIT software packages. The $k^{2}$-weighted EXAFS spectra were obtained by subtracting the post-edge background from the overall absorption and then normalizing with respect to the edgejump step. Subsequently, $k^{2}$-weighted $\chi(k)$ data of Ru $K$-edge were Fourier transformed to real $(R)$ space using a hanning windows $\left(\mathrm{d} k=1.0 \AA^{-1}\right)$ to separate the EXAFS contributions from different coordination shells. To obtain the quantitative structural parameters around central atoms, least-squares curve parameter fitting was performed using the ARTEMIS module of IFEFFIT software packages. The following EXAFS equation was used:

$$
\chi(k)=\sum_{j} \frac{N_{j} S_{o}^{2} F_{j}(k)}{k R_{j}^{2}} \exp \left[-2 k^{2} \sigma_{j}^{2}\right] \exp \left[\frac{-2 R_{j}}{\lambda(k)}\right] \sin \left[2 k R_{j}+\phi_{j}(k)\right]
$$

$S_{0}^{2}$ is the amplitude reduction factor, $F_{j}(k)$ is the effective curved-wave backscattering amplitude, $N_{j}$ is the number of neighbors in the $j^{\text {th }}$ atomic shell, $R_{j}$ is the distance between the X-ray absorbing central atom and the atoms in the $j^{\text {th }}$ atomic shell (backscatterer), $\lambda$ is the mean free path in $\AA, \phi_{j}(k)$ is the phase shift (including the phase shift for each shell and the total central atom phase shift), $\sigma_{j}$ is the Debye-Waller parameter of the $j^{\text {th }}$ atomic shell (variation of distances around the average $R_{j}$ ). The functions $F_{j}(k), \lambda$ and $\phi_{j}(k)$ were calculated with the ab initio code FEFF8.2. 


\section{Electrochemical Measurements}

All electrochemical data were measured using a typical three-electrode system of CHI760E electrochemical workstation. In the three-electrode system, we used glassy carbon electrode (5 $\mathrm{mm}$ in diameter) as the working electrode, $\mathrm{Ag} / \mathrm{AgCl}$ electrode and graphite rod as the reference electrode and counter electrode, respectively. In the preparation work, $5 \mathrm{mg}$ of electrocatalyst, $1000 \mu \mathrm{L}$ of ethanol and $15 \mu \mathrm{L}$ of $5 \mathrm{wt} \%$ Nafion solution were mixed together and sonicated for $30 \mathrm{~min}$ to make the catalyst uniformly dispersed. Then $15 \mu \mathrm{L}$ of catalyst ink was evenly dropped on the surface of the glassy carbon electrode and dried at room temperature to ensure the catalyst loading of $0.38 \mathrm{mg} \mathrm{cm}^{-2}$ for all electrochemical reactions (ORR/OER). The test potential of ORR and OER was finally converted into the reversible hydrogen electrode (RHE) by the following equation :

$$
E(v s . R H E)=E(v s . A g / A g C l)+0.059 \times P H+0.196
$$

For ORR, all LSV curves of different rotation speeds (400 rpm-2025 rpm) were tested in an $\mathrm{O}_{2}$ saturated $0.1 \mathrm{M} \mathrm{KOH}$ media at a scan rate of $10 \mathrm{mV} \mathrm{s}^{-1}$. The $\mathrm{CV}$ curves were measured in $\mathrm{O}_{2}$ saturated and $\mathrm{N}_{2}$ saturated $0.1 \mathrm{M} \mathrm{KOH}$ media. The accelerated durability test was conducted from $0.66 \mathrm{~V}$ to $0.96 \mathrm{~V}$ at a scan rate of $50 \mathrm{mV} / \mathrm{s}$. Electrochemical impedance spectroscopy (EIS) was tested in the frequency range of $100 \mathrm{KHz}$ to $10 \mathrm{mHz}$. Methanol tolerance was measured by LSV, CV and chronoamperometry by injecting different contents of methanol into the electrolyte. The Koutecky-Levich (K-L) plots were evaluated according to the following equation :

$$
\begin{aligned}
& \frac{1}{J}=\frac{1}{J_{k}}+\frac{1}{J_{L}}=\frac{1}{B w^{1 / 2}}+\frac{1}{J_{k}} \\
& B=0.62 n F C_{0} D_{0}^{2 / 3} V^{-1 / 6}
\end{aligned}
$$

where $J, J_{k}$ and $J_{L}$ denote the measurement current, kinetic current and limit current, respectively, and $w, n, F, C_{0}, D_{0}$ and $v$ are the angular velocity of the disk, the number of electron transfer, the Faraday constant $\left(96485 \mathrm{C} \mathrm{mol}^{-1}\right)$, the volume concentration of $\mathrm{O}_{2}\left(1.2 \times 10^{-6} \mathrm{~mol} \mathrm{~cm} \mathrm{~cm}^{-3}\right)$, the diffusion coefficient of $\mathrm{O}_{2}\left(1.9 \times 10^{-5} \mathrm{~cm}^{2} \mathrm{~s}^{-1}\right)$ and the kinematic viscosity of the electrolyte $\left(0.01 \mathrm{~cm}^{2} \mathrm{~s}^{-1}\right)$, respectively. In addition, the 
electron transfer number and hydrogen peroxide yield can be calculated according to the following formula :

$$
\begin{gathered}
n=4 \times \frac{I_{d}}{I_{d}+I_{r} / N_{c}} \\
H_{2} O_{2} \%=200 \frac{I_{r} / N_{c}}{I_{d}+I_{r} / N_{c}} \%
\end{gathered}
$$

where $I_{d}, I_{r}$ and $N_{c}$ are the disk current, ring current and the collection efficiency of the ring disk electrode (0.424), respectively. For OER, all LSV curves were tested in an $\mathrm{N}_{2}$ saturated $1 \mathrm{M} \mathrm{KOH}$ media at a scan rate of $10 \mathrm{mV} \mathrm{s}^{-1}$. The accelerated durability test was conducted from $1.02 \mathrm{~V}$ to $1.82 \mathrm{~V}$. The $\mathrm{CV}$ curves at different scan rate were measured to determine the electrochemical double layer capacitance $\left(\mathrm{C}_{\mathrm{dl}}\right)$ and ESCAs.

\section{Liquid Zn-air battery assembly}

A self-made simple liquid Zn-air battery was built by using carbon paper coated with the $\mathrm{FeCo} / \mathrm{Se}-\mathrm{CNT}$ catalyst as the air cathode, $\mathrm{Zn}$ foil as the anode, and $6 \mathrm{M} \mathrm{KOH}$ and $0.2 \mathrm{M} \mathrm{Zn}(\mathrm{OAc})_{2}$ (ensure reversible $\mathrm{Zn}$ foil reaction) as the electrolyte. The effective contact area between the catalyst and the electrolyte coated on carbon paper is $1 \mathrm{~cm}^{2}$. The mass loading of the FeCo/Se-CNT catalyst on carbon paper was about $2 \mathrm{mg} \mathrm{cm}^{-2}$. In addition, $\mathrm{Pt} / \mathrm{C}$ and $\mathrm{RuO}_{2} / \mathrm{C}$ were mixed at a molar ratio of $1: 1$ as control sample. The specific capacity could be calculated according to the following equation :

$$
\text { specific capacity }=\frac{\text { discharge current } \times \text { service hours }}{\text { weight of consumed } \mathrm{Zn}}
$$

\section{Flexible All-Solid-State Zn-air battery assembly}

The flexible all-solid-state Zn-air battery consists of carbon cloth (cathode, current collector) coated with the the $\mathrm{FeCo} / \mathrm{Se}-\mathrm{CNT}$ catalyst, $\mathrm{Zn}$ foil (anode) and solid polymer electrolyte. The loading area of the catalyst is controlled within the area of $1 \times 2 \mathrm{~cm}^{2}$. After assembling the carbon cloth, electrolyte and Zn foil into a solid Zn-air battery, it was simply wrapped with aluminum plastic film. During the preparation of polymer electrolyte, $1 \mathrm{~g}$ PVA was dissolved in $20 \mathrm{ml}$ deionized water at $95{ }^{\circ} \mathrm{C}$ with magnetic 
stirring for $1 \mathrm{~h}$. Then $4 \mathrm{ml}$ mixed solution of $18 \mathrm{M} \mathrm{KOH}$ and $0.02 \mathrm{M} \mathrm{Zn}(\mathrm{OAc})_{2}$ was added. After stirring $1 \mathrm{~h}$, the mixture was poured into a rectangular mold and placed in the refrigerator for 4 hours at $-20{ }^{\circ} \mathrm{C}$. The test methods of solid flexible $\mathrm{Zn}$-air battery and liquid Zn-air battery were exactly the same. 
2. Supplementary Figures and Tables
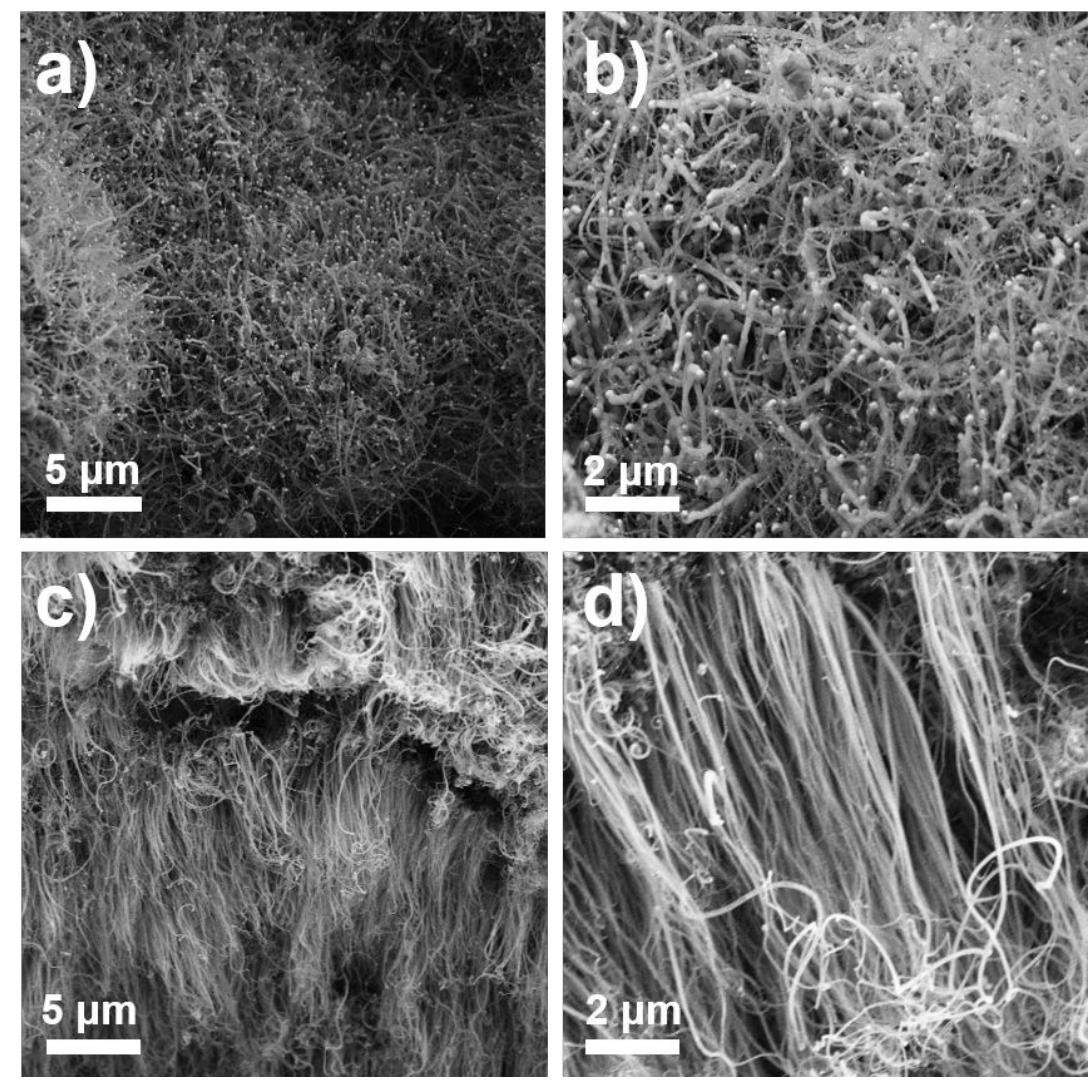

Figure S1. (a-d) SEM images of the FeCo/Se-CNT catalyst. 


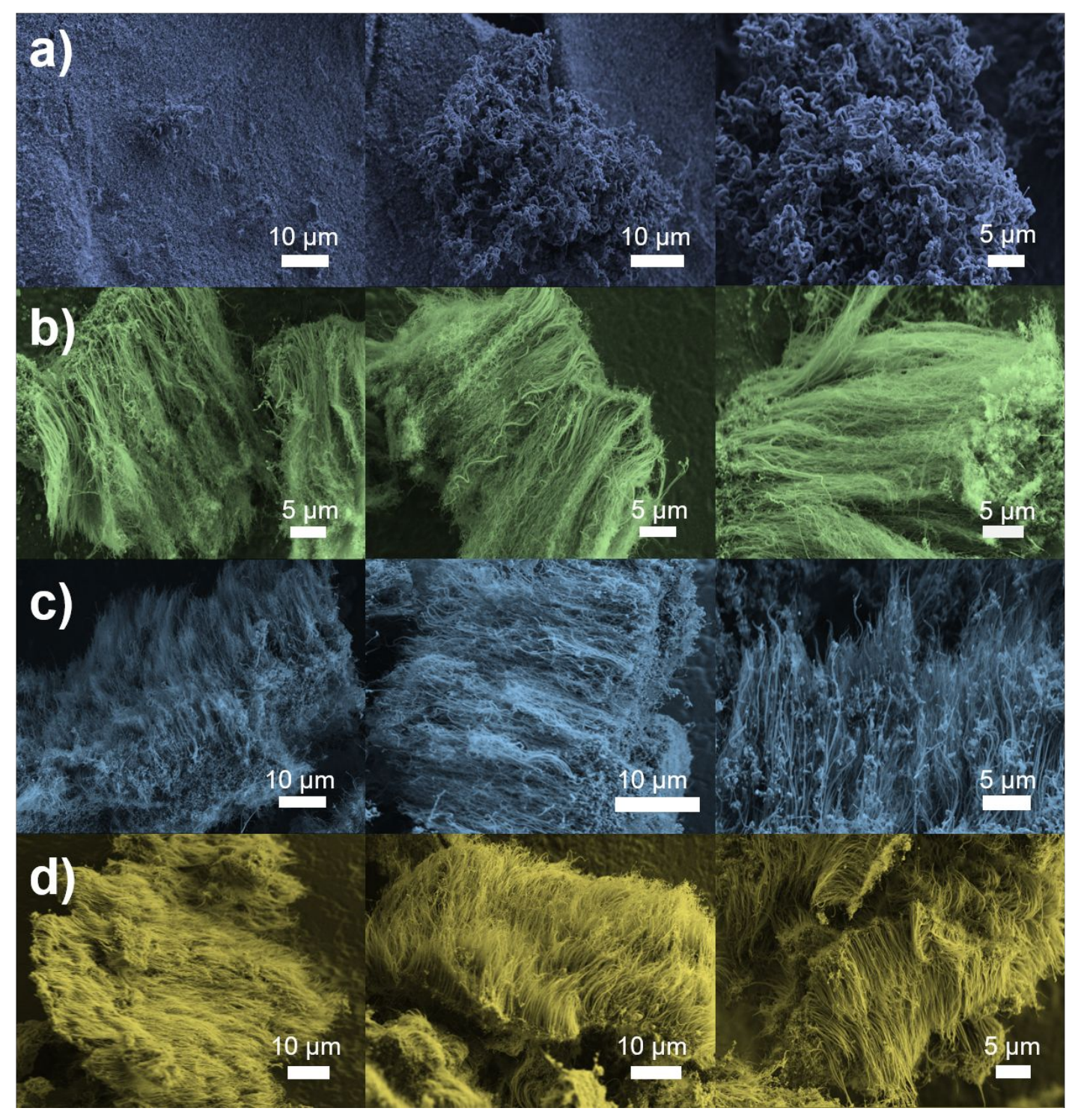

Figure S2. SEM images of grown carbon nanotubes via a gravity guided CVD strategy under the conditions of $1 \mathrm{~g}(\mathrm{a}), 3 \mathrm{~g}(\mathrm{~b}), 5 \mathrm{~g}$ (c) and $7 \mathrm{~g}(\mathrm{~d})$ melamine. 

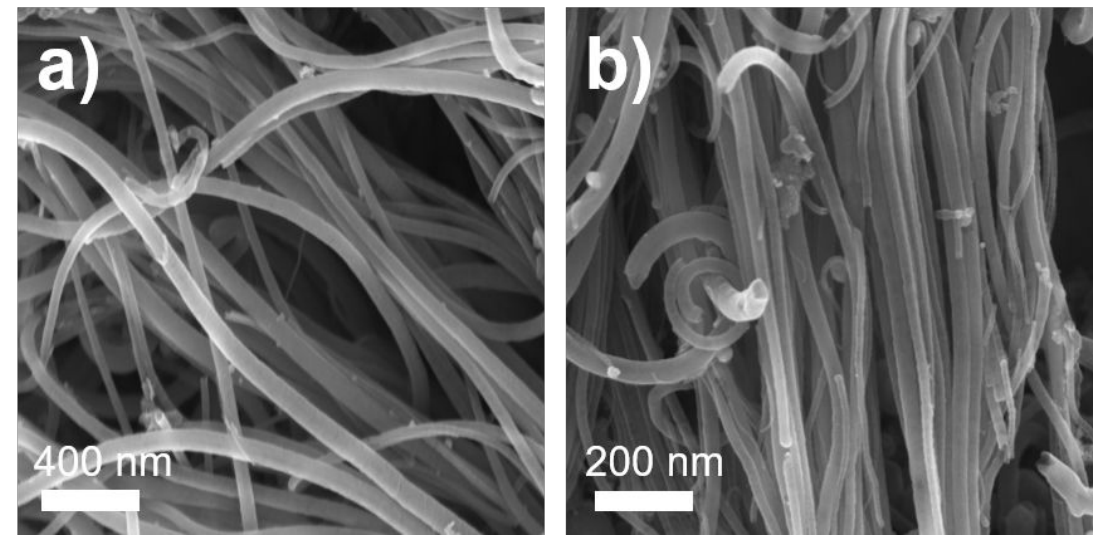

Figure S3. (a, b) SEM images of the FeCo/Se-CNT catalyst.
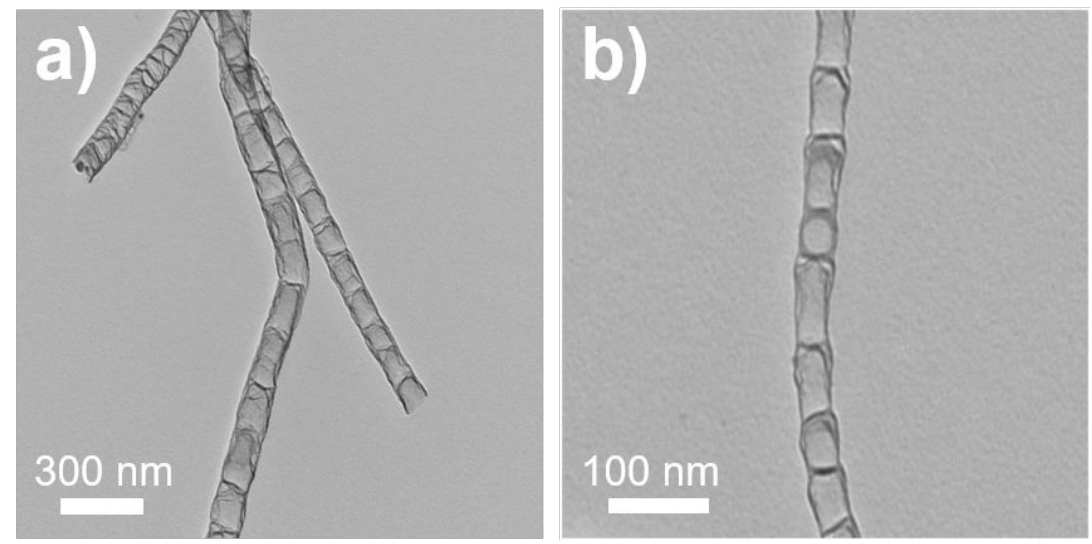

Figure S4. (a, b) TEM images of the FeCo/Se-CNT catalyst. 


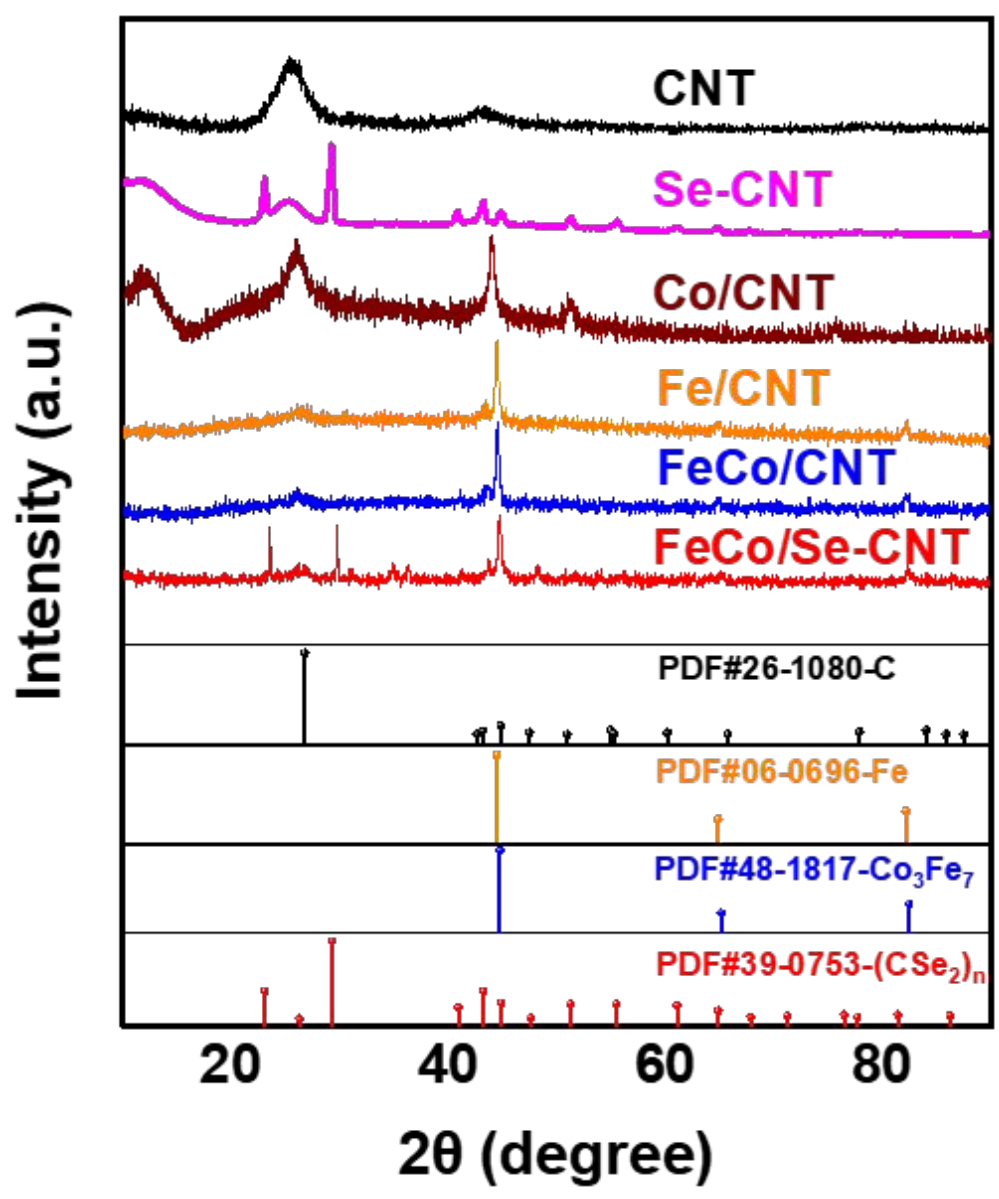

Figure S5. PXRD patterns of the FeCo/Se-CNT, FeCo/CNT, Fe/CNT, Co/CNT, SeCNT and CNT catalysts. 


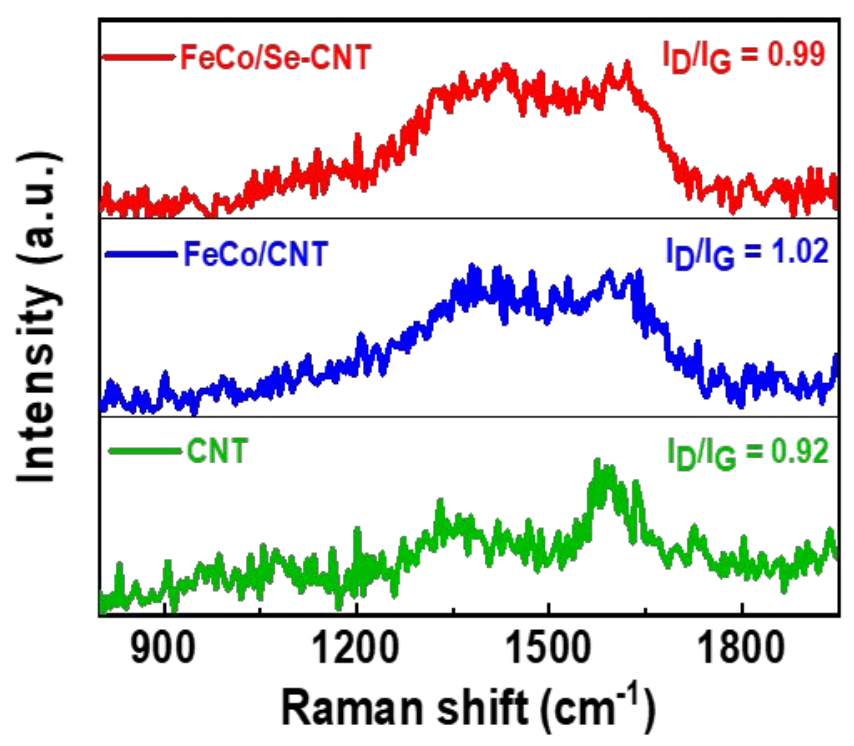

Figure S6. Raman spectra of the $\mathrm{CNT}, \mathrm{FeCo} / \mathrm{CNT}$ and $\mathrm{FeCo} / \mathrm{Se}-\mathrm{CNT}$ catalysts.

a)

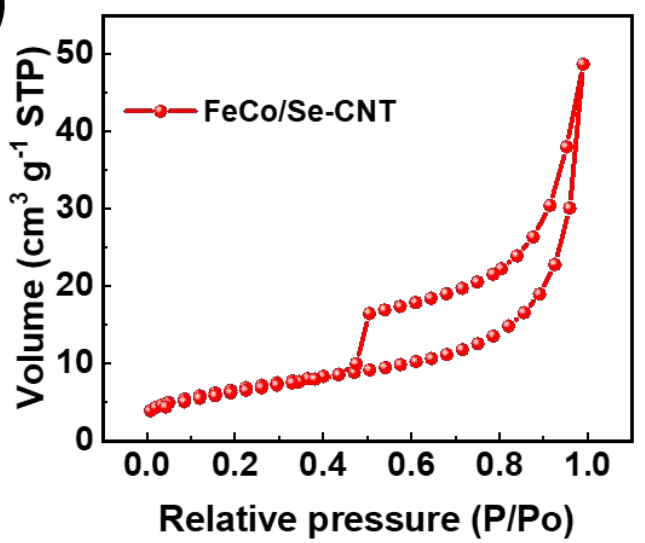

b)

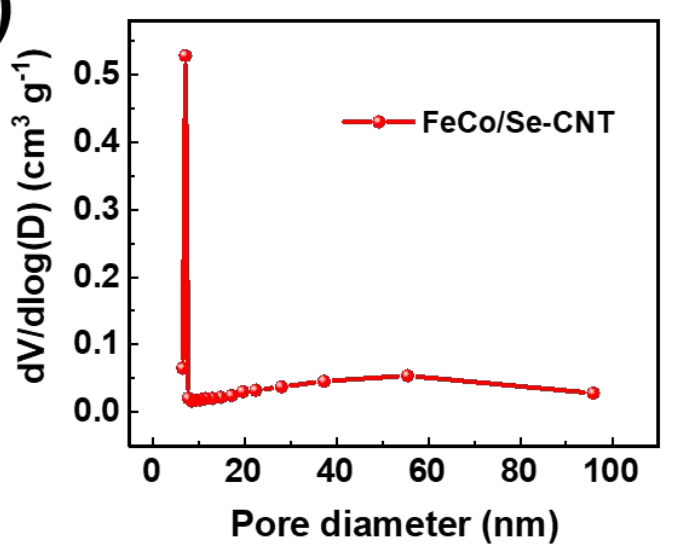

Figure S7. (a) $\mathrm{N}_{2}$ adsorption desorption isotherm and (b) pore size distributions of the $\mathrm{FeCo} / \mathrm{Se}-\mathrm{CNT}$ catalyst. 


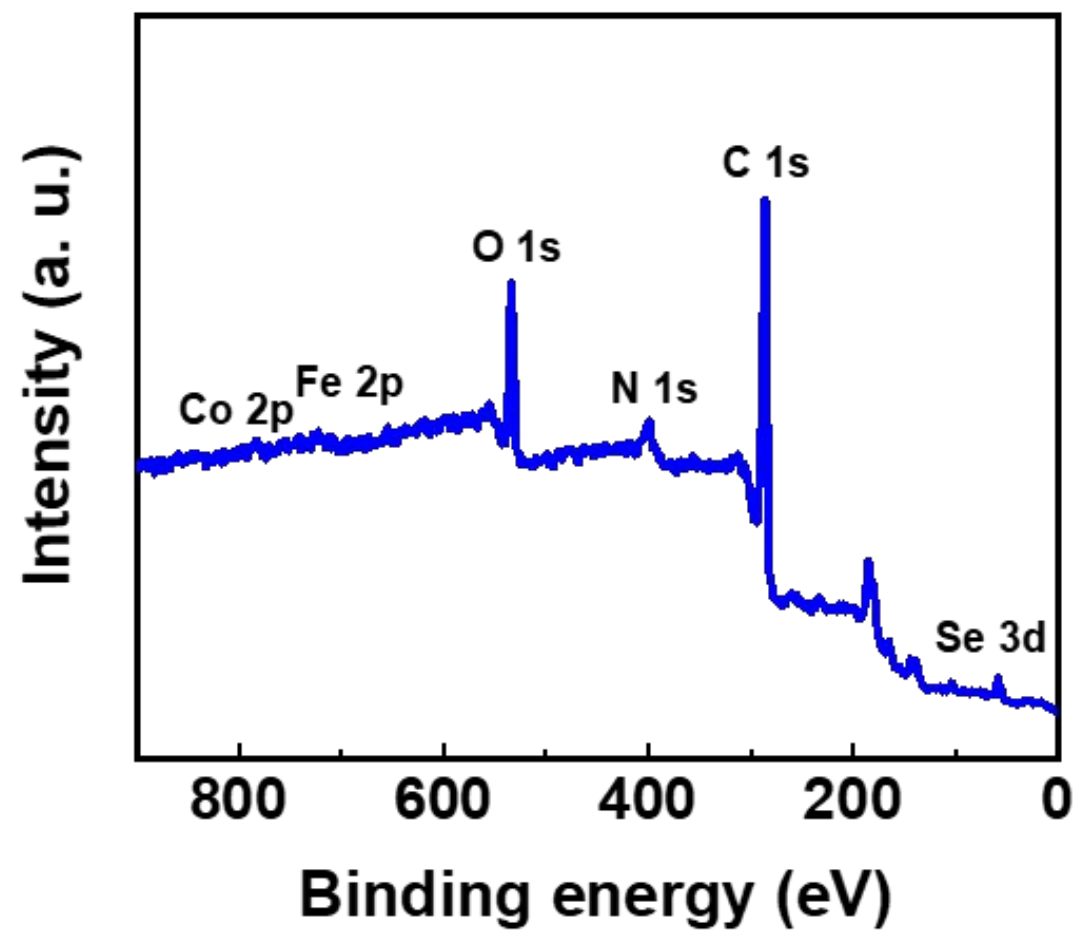

Figure S8. XPS full spectrum of the FeCo/Se-CNT catalyst.
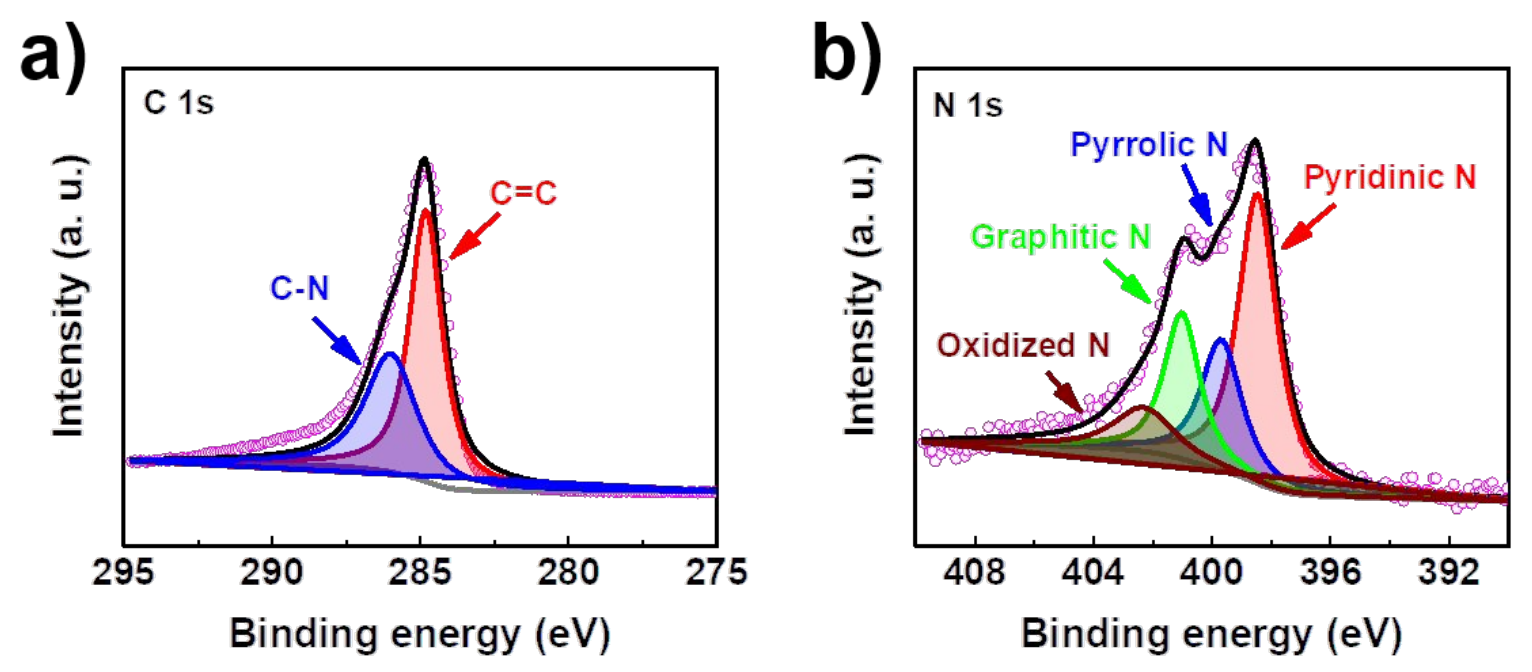

Figure S9. The C 1s (a) and N 1s (b) spectra of the FeCo/CNT catalyst. 


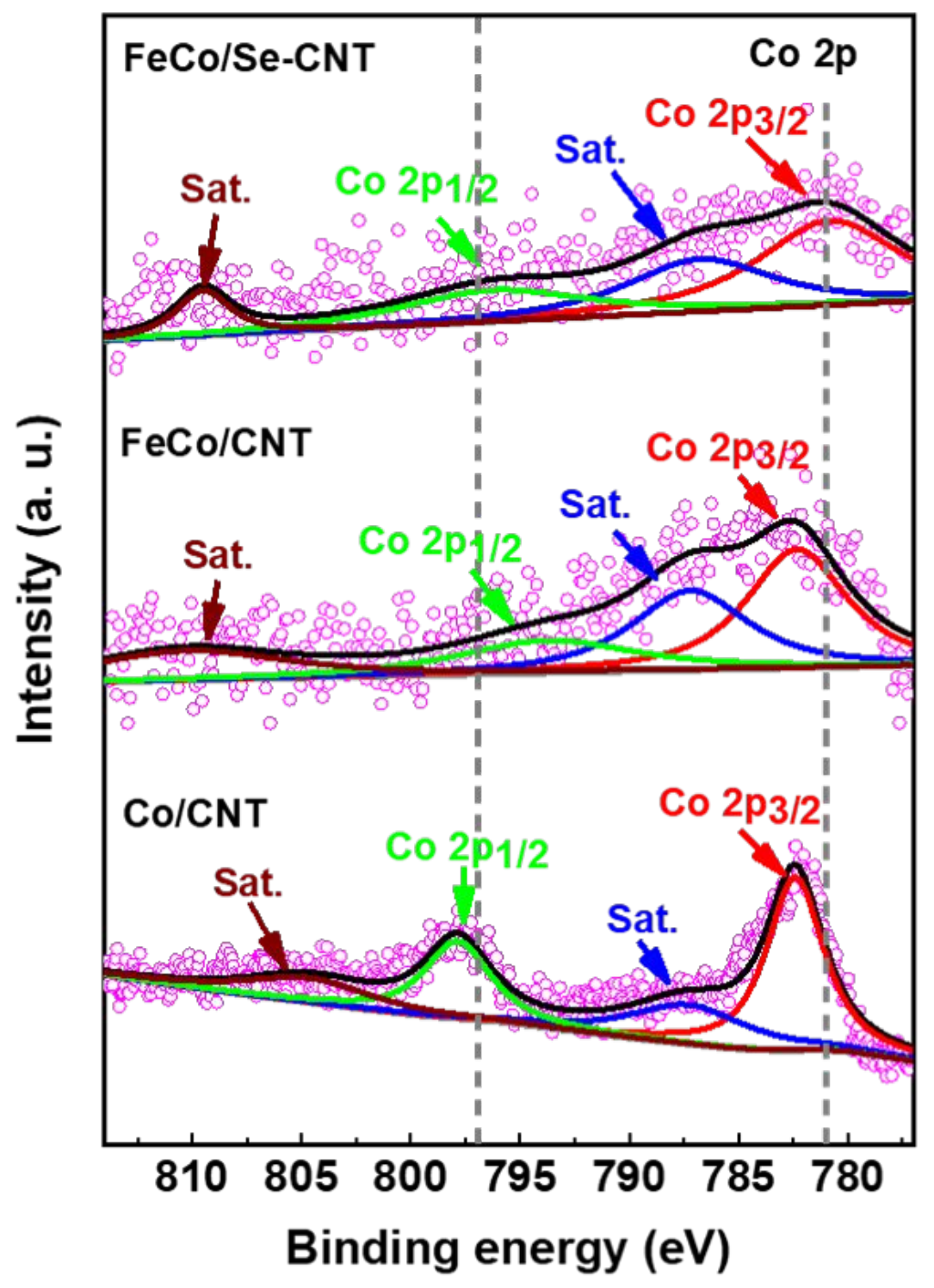

Figure S10. XPS Co 2p spectra of the $\mathrm{FeCo} / \mathrm{Se}-\mathrm{CNT}, \mathrm{FeCo} / \mathrm{CNT}$ and $\mathrm{Co} / \mathrm{CNT}$ catalysts. 


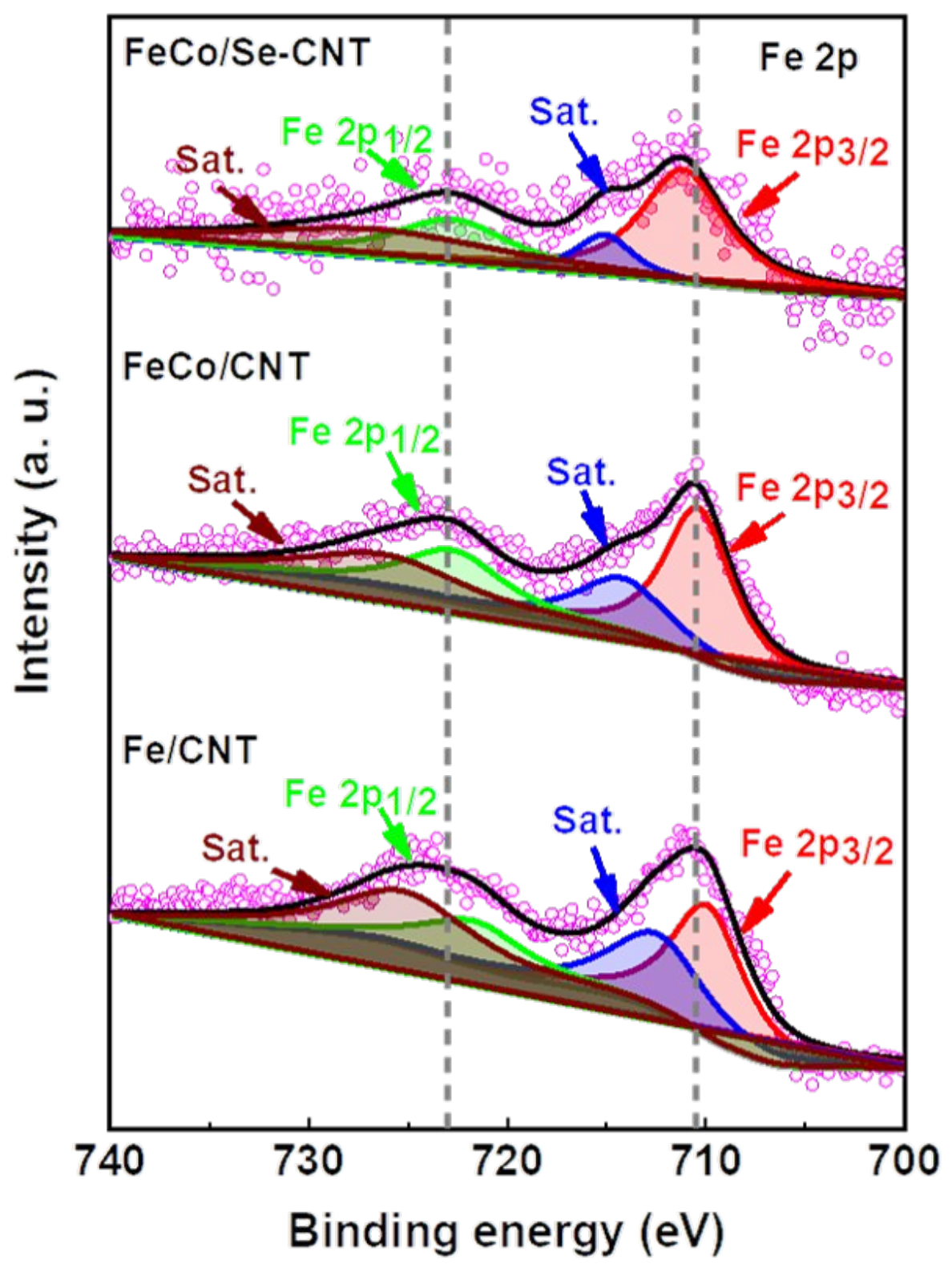

Figure S11. XPS Fe 2p spectra of the FeCo/Se-CNT, FeCo/CNT and Fe/CNT catalysts. 
a)

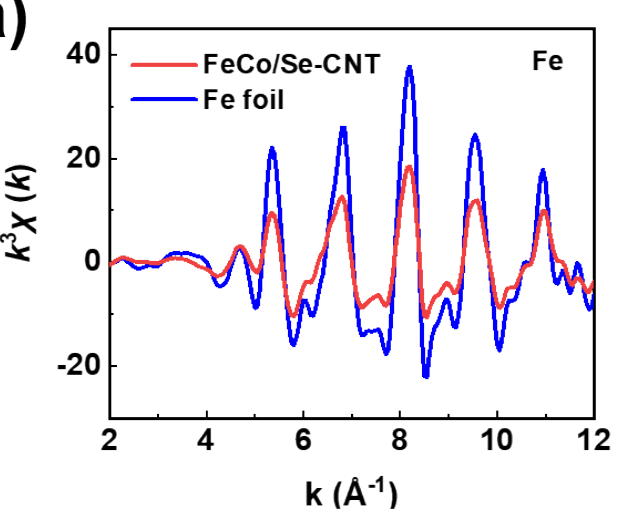

c)

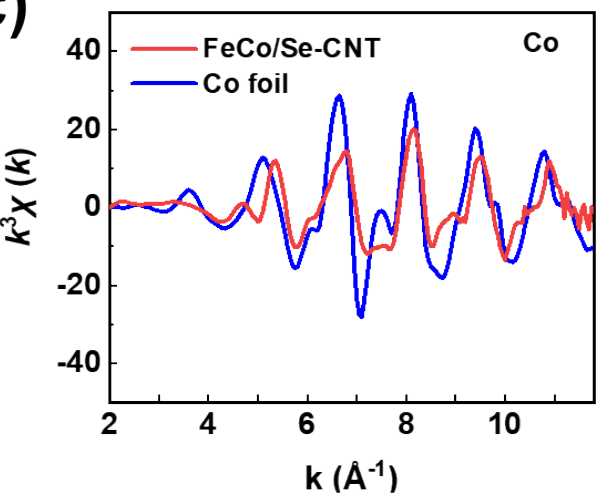

b)

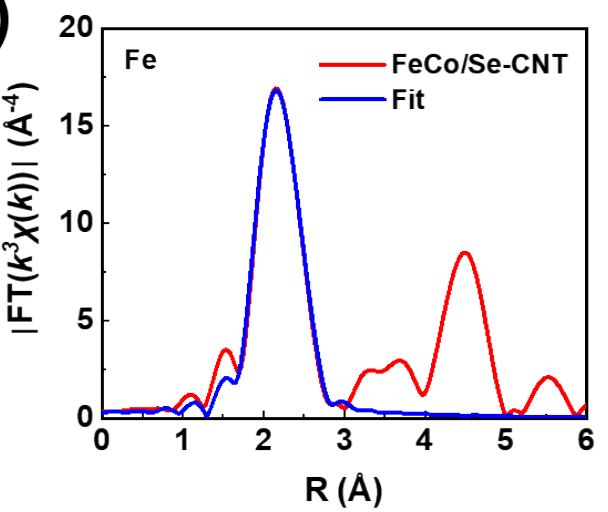

d)

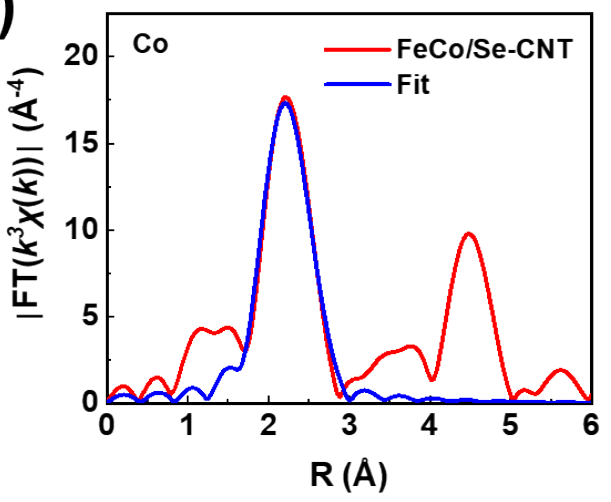

Figure S12. The corresponding Fe K-edge (a-b) and Co K-edge (c-d) $k$ space and EXAFS $R$ fitting curves of the FeCo/Se-CNT catalyst.

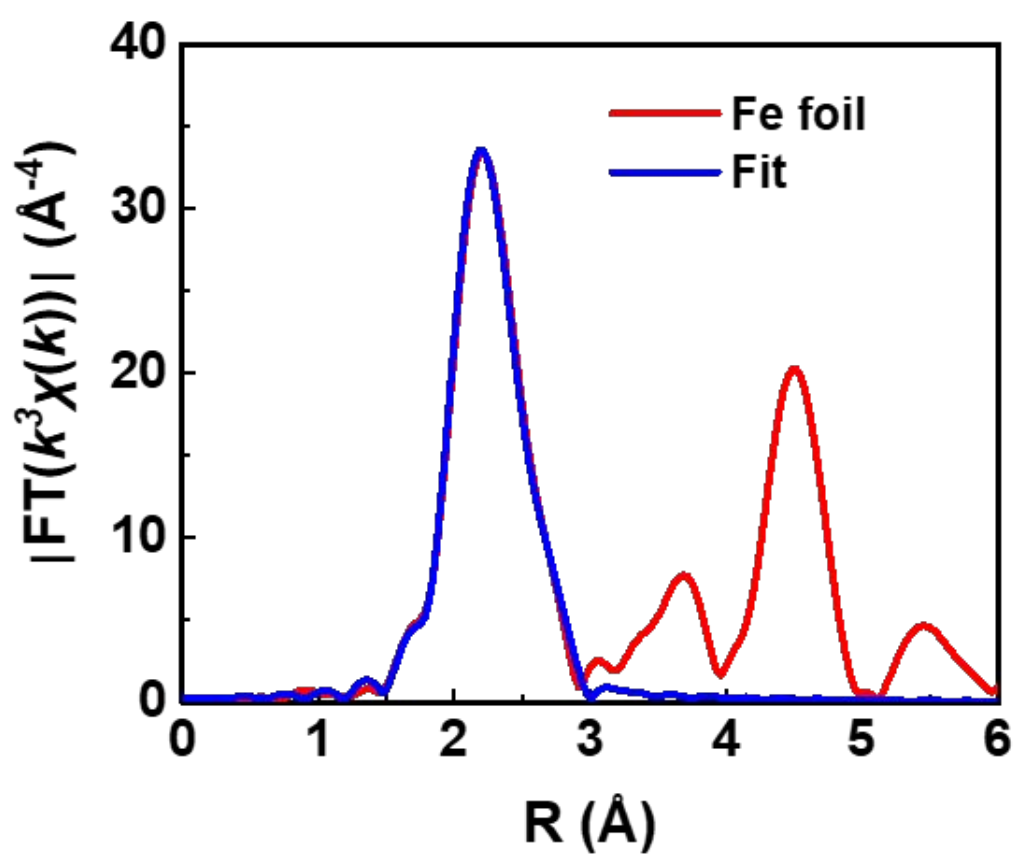

Figure S13. The corresponding EXAFS fitting curves of Fe foil. 


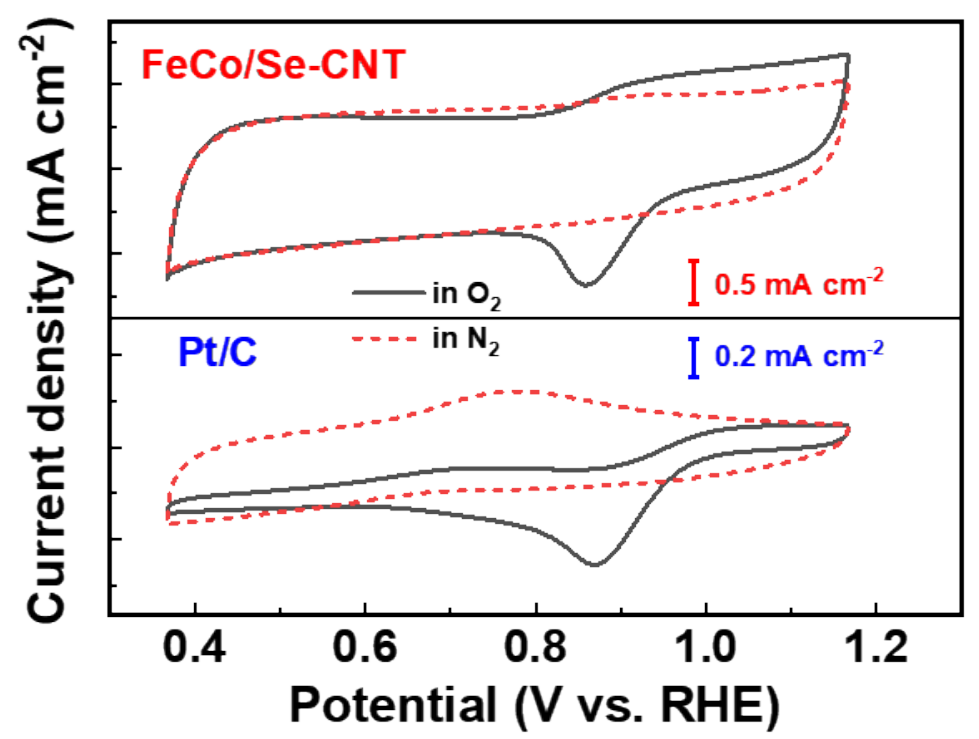

Figure S14. $\mathrm{CV}$ curves of the $\mathrm{FeCo} / \mathrm{Se}-\mathrm{CNT}$ and commercial $\mathrm{Pt} / \mathrm{C}$ catalysts in $\mathrm{O}_{2}$ and $\mathrm{N}_{2}$ saturated $0.1 \mathrm{M} \mathrm{KOH}$ media.

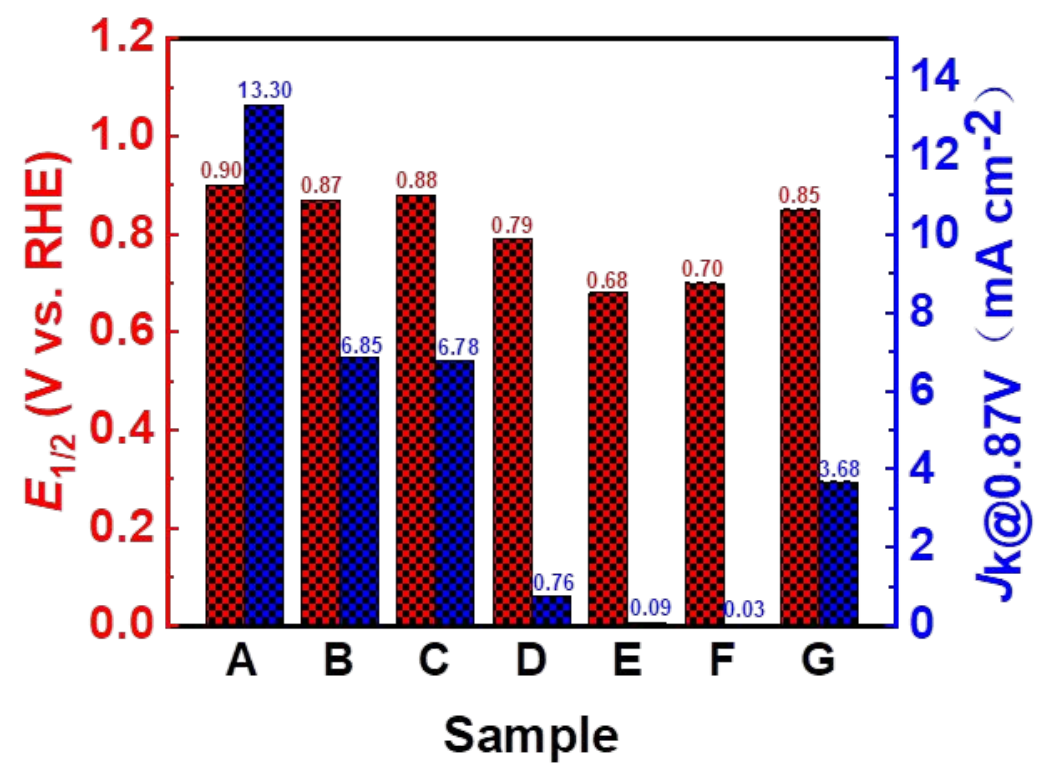

Figure S15. Summary of $E_{1 / 2}$ and $J_{\mathrm{K} @ 0.87 \mathrm{~V}}$ for the $\mathrm{FeCo} / \mathrm{Se}-\mathrm{CNT}(\mathrm{A}), \mathrm{FeCo} / \mathrm{CNT}$ (B), $\mathrm{Fe} / \mathrm{CNT}(\mathrm{C}), \mathrm{Co} / \mathrm{CNT}(\mathrm{D}), \mathrm{Se}-\mathrm{CNT}(\mathrm{E}), \mathrm{CNT}(\mathrm{F})$ and Pt/C (G) catalysts, respectively. 
a)

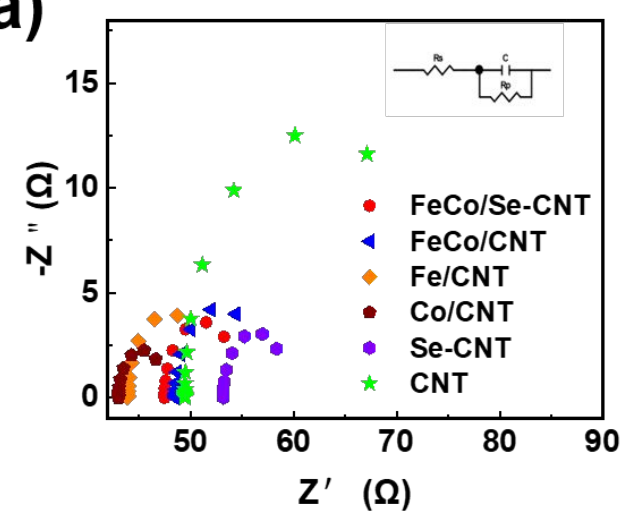

b)

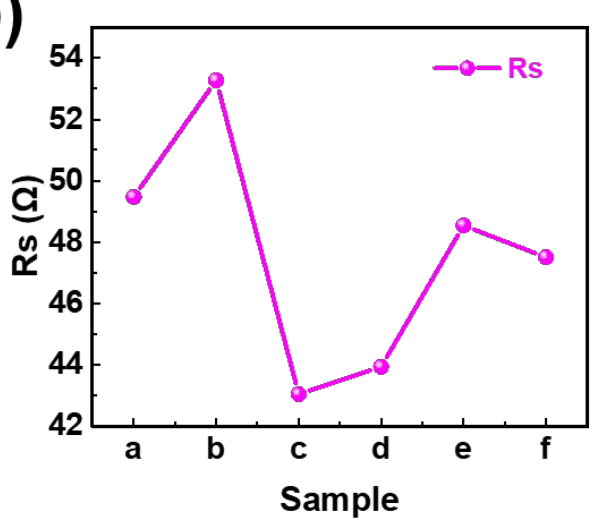

Figure S16. (a) Nyquist plots and (b) Ohm resistance in $0.1 \mathrm{M} \mathrm{KOH}$ media for ORR, respectively. (Rs: ohm resistance, $\mathrm{Rp}$ : charge transfer resistance, C: capacity) (a-f stand for CNT, Se-CNT, Co/CNT, Fe/CNT, FeCo/CNT, and FeCo/Se-CNT, respectively).

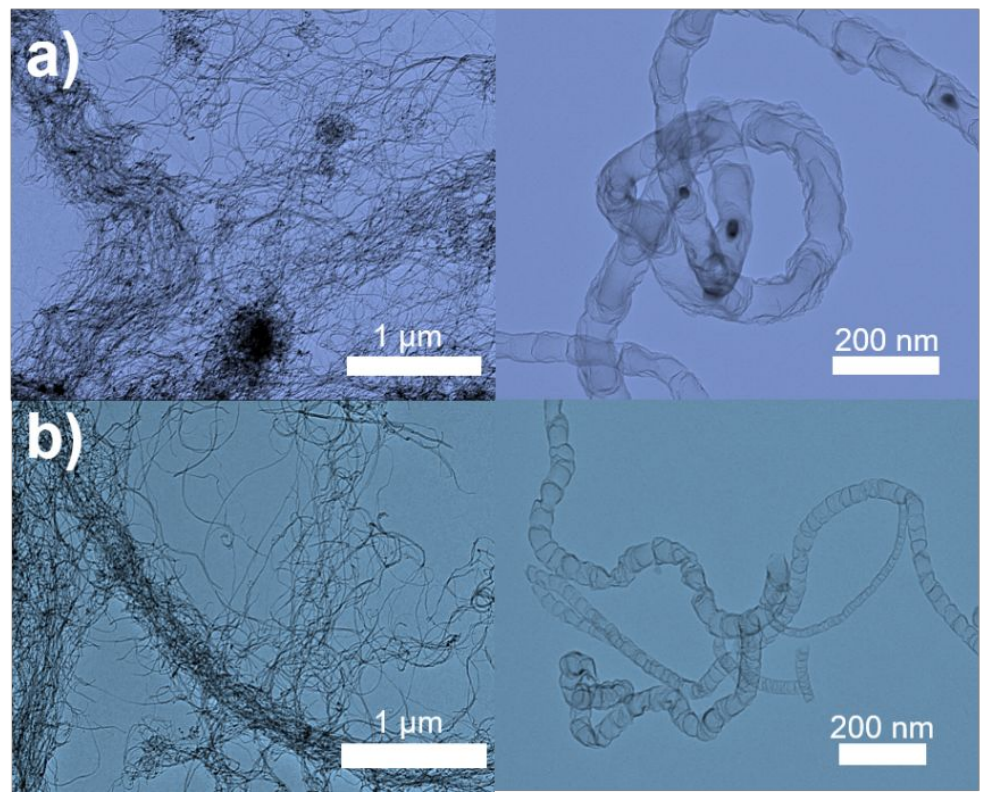

Figure S17. TEM images of the untreated $\mathrm{FeCo} / \mathrm{CNT}$ catalyst (a) and acid etching $\mathrm{FeCo} / \mathrm{CNT}$ catalyst (b). 


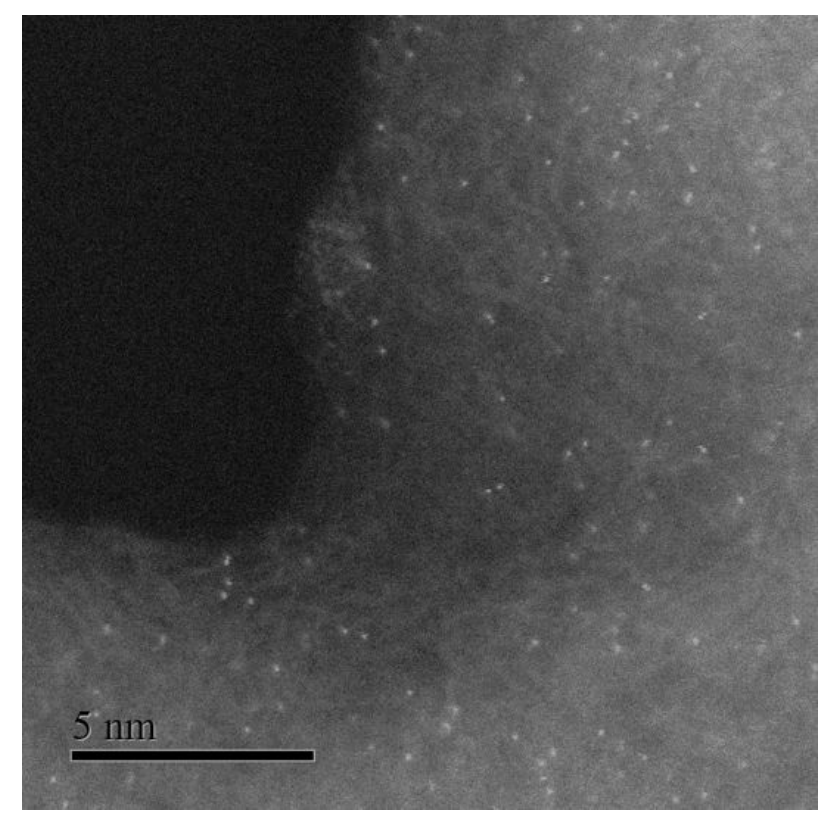

Figure S18. AC HRTEM images of acid etching FeCo/CNT catalyst.

a)

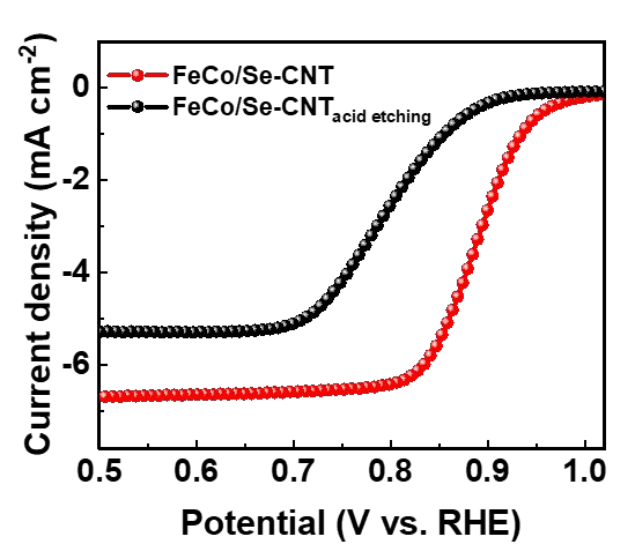

b)

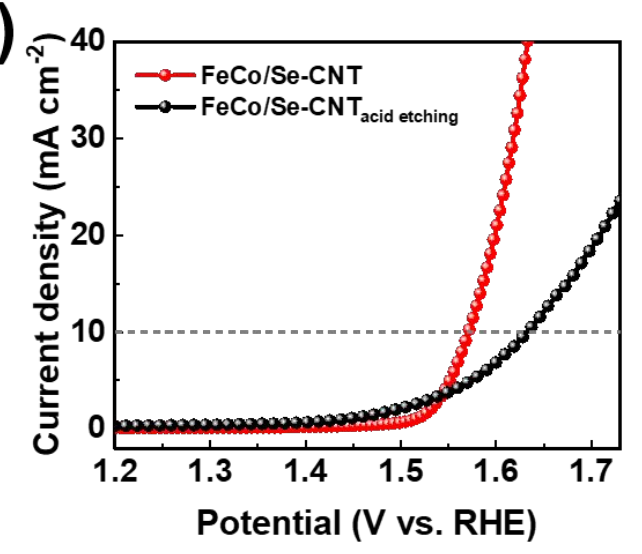

Figure S19. LSV polarization curves for ORR (a) and OER (b) of the FeCo/Se-CNT and $\mathrm{FeCo} / \mathrm{Se}-\mathrm{CNT}_{\text {acid etching }}$ catalyst. 


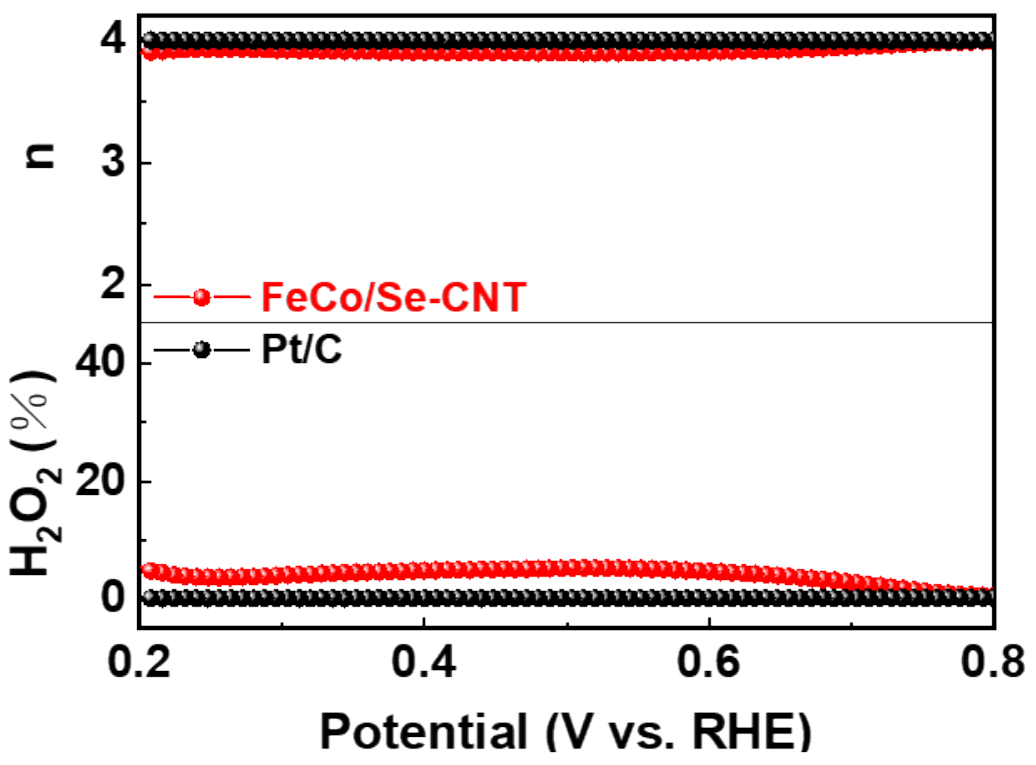

Figure S20. $\mathrm{H}_{2} \mathrm{O}_{2}$ yield and electron transfer number of the $\mathrm{FeCo} / \mathrm{Se}-\mathrm{CNT}$ and cammercial $\mathrm{Pt} / \mathrm{C}$ catalysts.

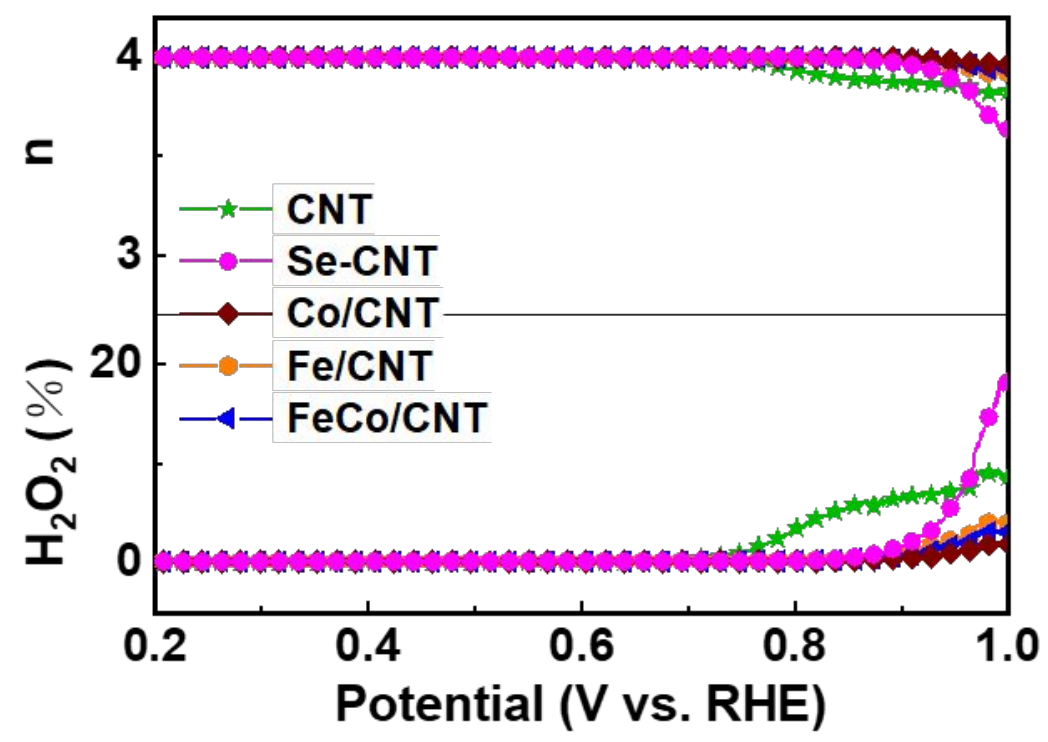

Figure S21. $\mathrm{H}_{2} \mathrm{O}_{2}$ yield and electron transfer number of control samples. 
a)

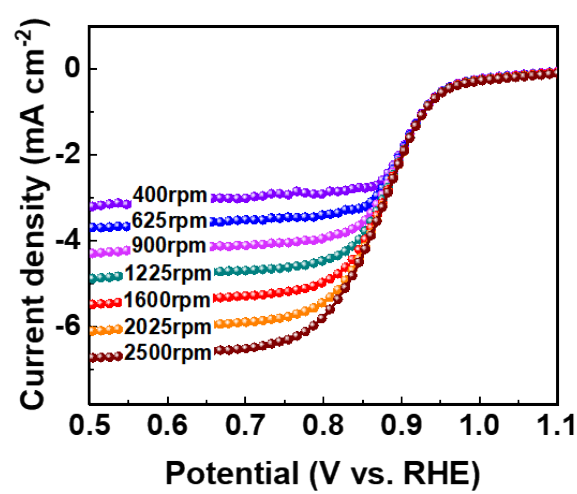

b)

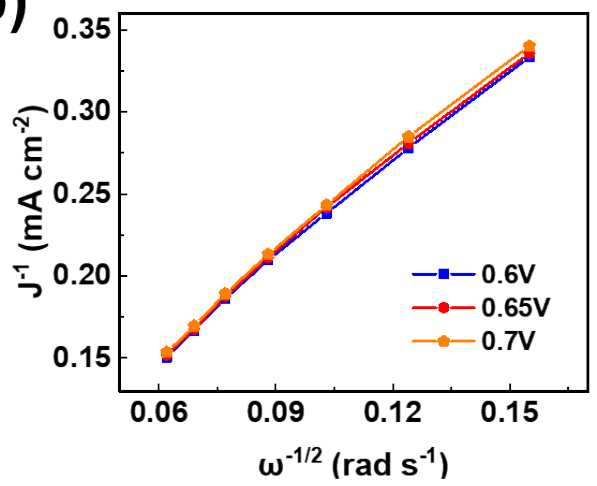

Figure S22. LSV curves at various rotation speeds and Koutecky-Levich $(\mathrm{K}-\mathrm{L})$ plots of the $\mathrm{FeCo} / \mathrm{Se}-\mathrm{CNT}$ catalyst in $\mathrm{O}_{2}$ saturated $0.1 \mathrm{M} \mathrm{KOH}$ media.

a)

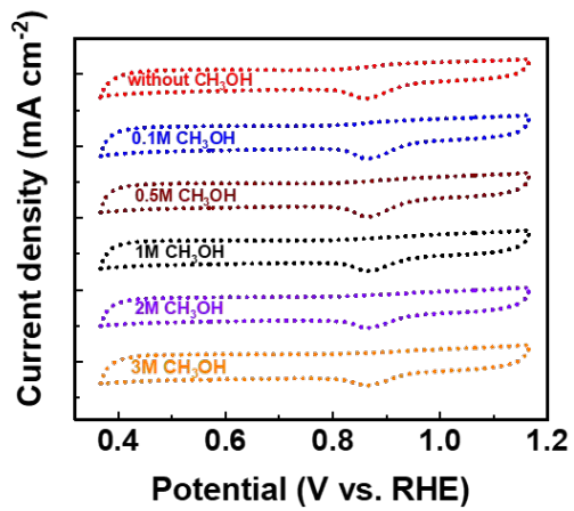

b)

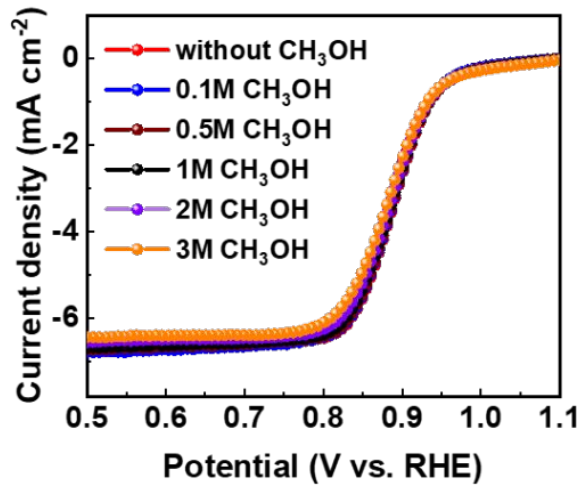

Figure S23. CV and LSV curves with different concentrations of methanol. 


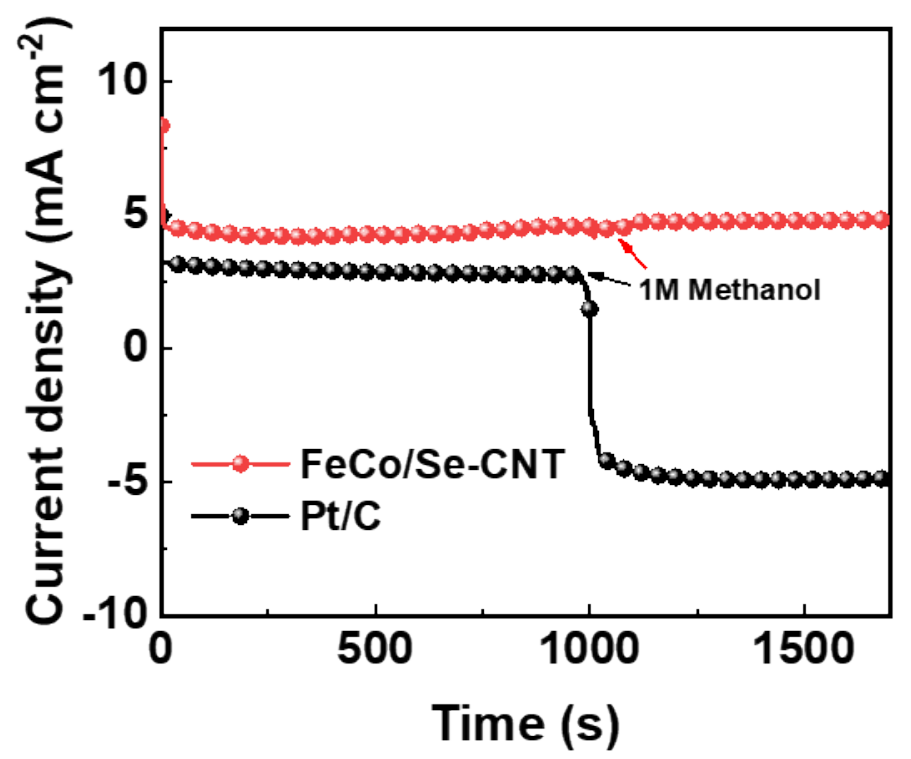

Figure S24. Chronoamperometric responses with 1M methanol.

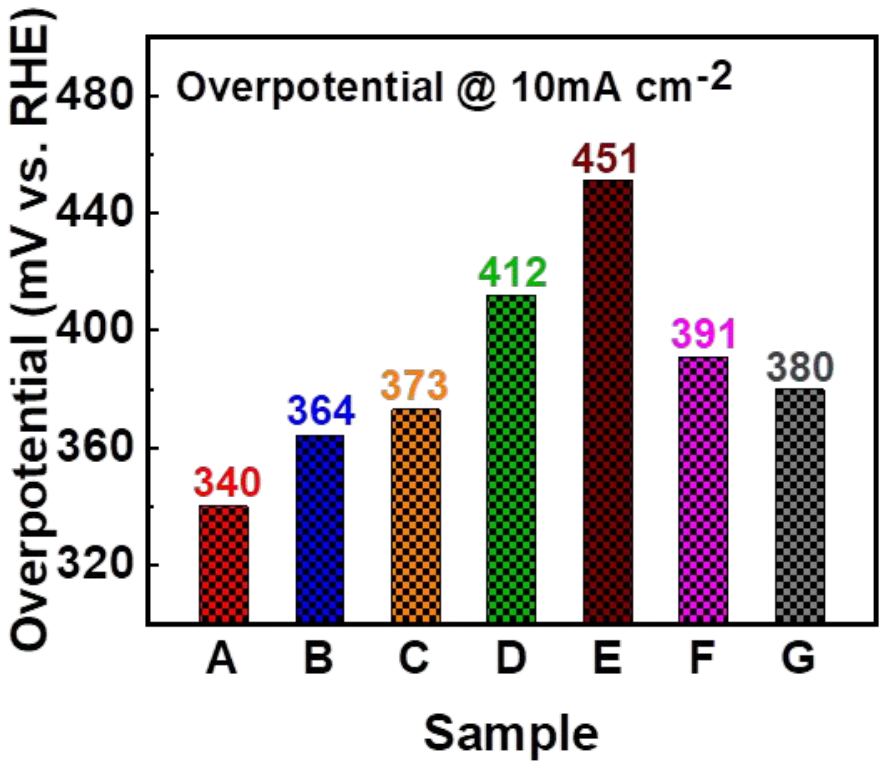

Figure S25. Summary of overpotential at $10 \mathrm{~mA} \mathrm{~cm}^{-2}$ for the $\mathrm{FeCo} / \mathrm{Se}-\mathrm{CNT}$ (A), $\mathrm{FeCo} / \mathrm{CNT}(\mathrm{B}), \mathrm{Fe} / \mathrm{CNT}(\mathrm{C}), \mathrm{Co} / \mathrm{CNT}(\mathrm{D}), \mathrm{Se}-\mathrm{CNT}(\mathrm{E}), \mathrm{CNT}(\mathrm{F})$ and $\mathrm{RuO}_{2} / \mathrm{C}(\mathrm{G})$ catalysts, respectively. 
a)

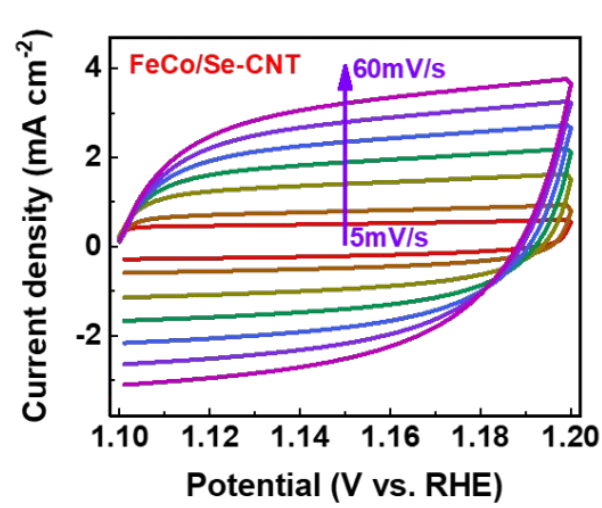

c)

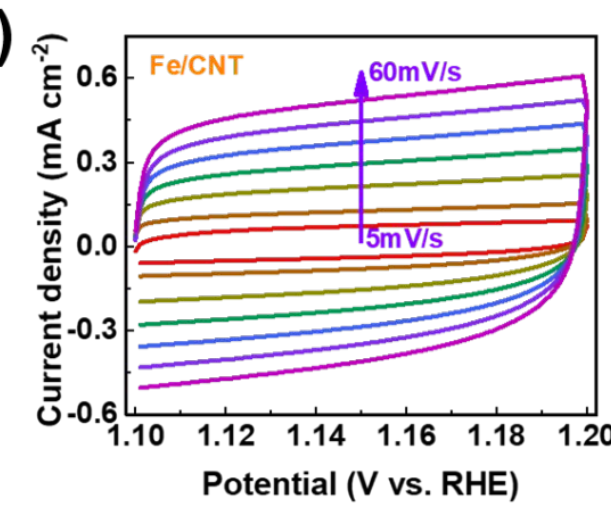

b)

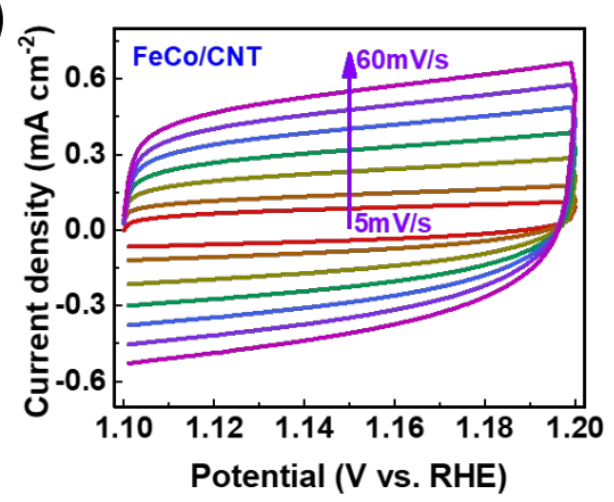

d)

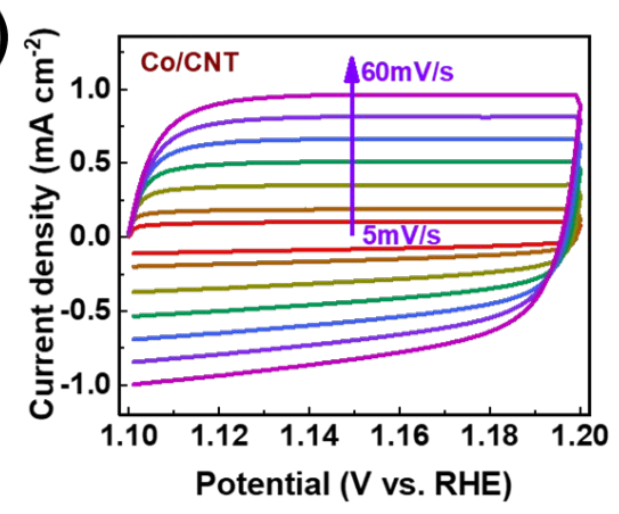

e)

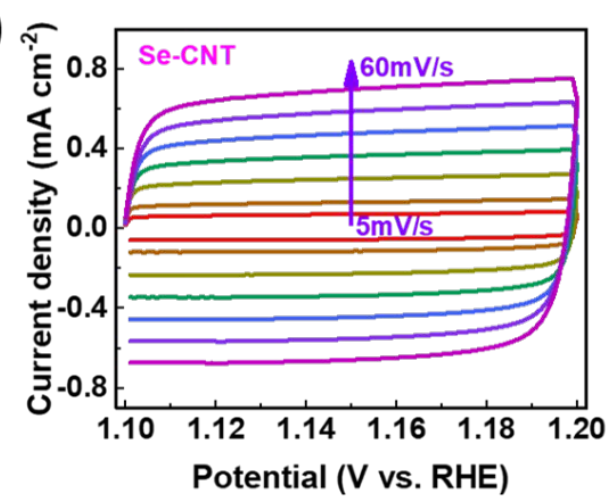

g)

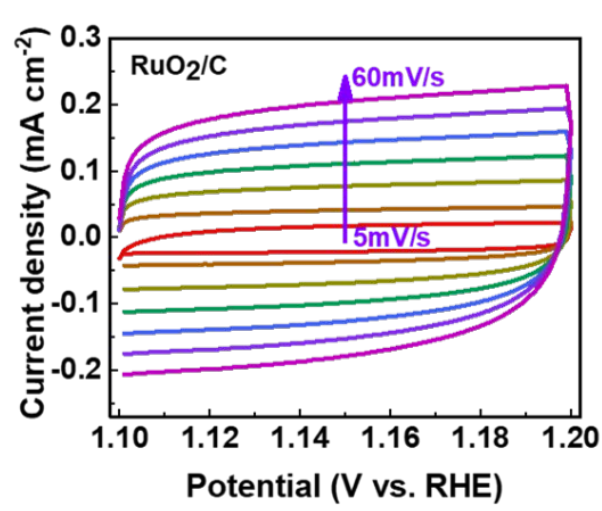

f)

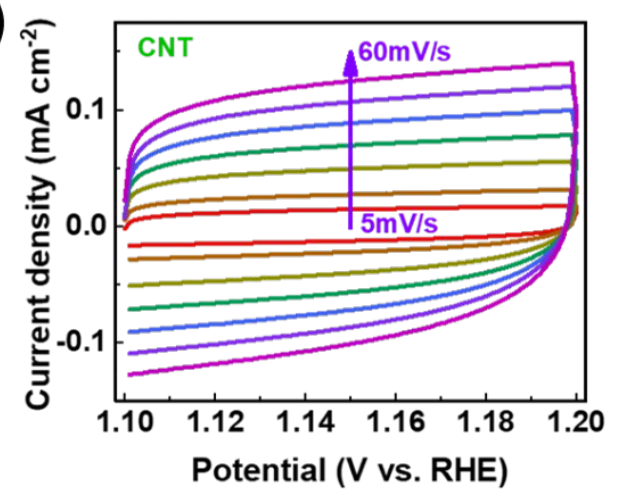

h)

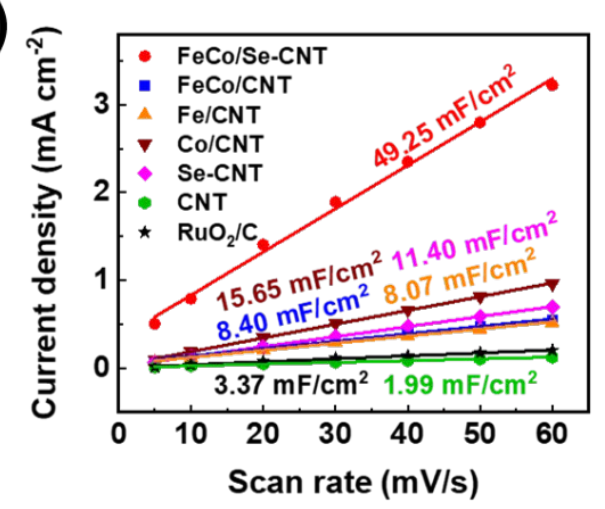

Figure S26. CV curves of the FeCo/Se-CNT (a), FeCo/CNT (b), Fe/CNT (c), $\mathrm{Co} / \mathrm{CNT}$ (d), Se-CNT (e), CNT (f) and $\mathrm{RuO}_{2} / \mathrm{C}$ (g) catalysts in $1 \mathrm{M} \mathrm{KOH}$ media for OER (1.1-1.2 V). (h) Current density versus scan rate. 

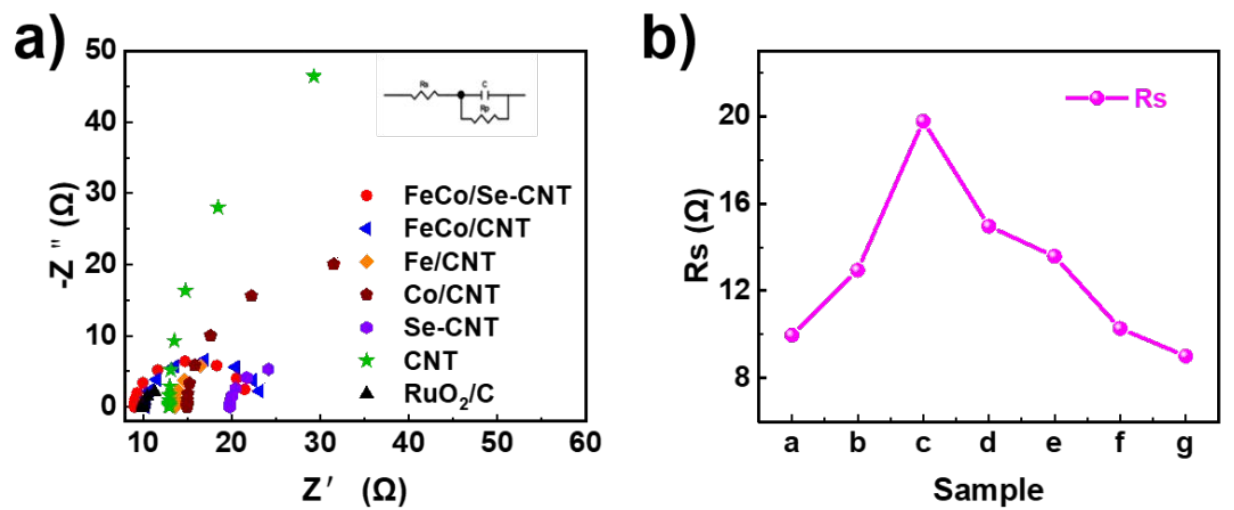

Figure S27. (a) Nyquist plots and (b) Ohm resistance in $1 \mathrm{M} \mathrm{KOH}$ media for OER, respectively. (Rs: ohm resistance, Rp: charge transfer resistance, C: capacity) (a-g stand for $\mathrm{RuO}_{2} / \mathrm{C}, \mathrm{CNT}$, Se-CNT, Co/CNT, Fe/CNT, FeCo/CNT, and FeCo/Se-CNT, respectively).

a)

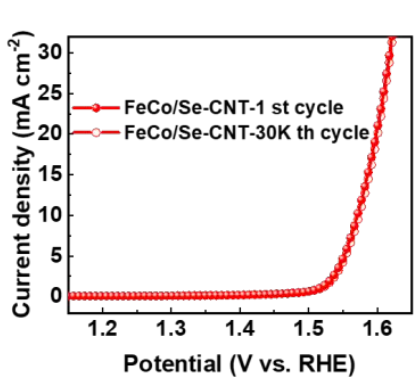

c)

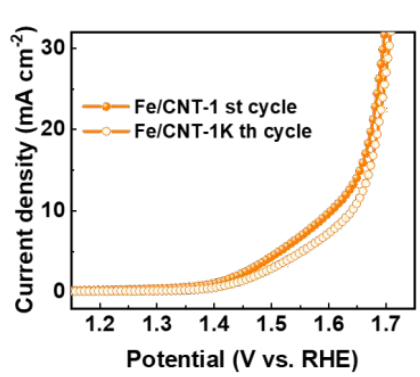

e)

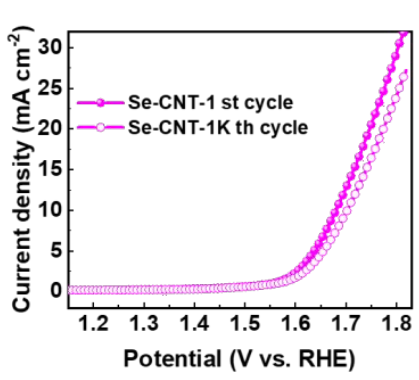

b)

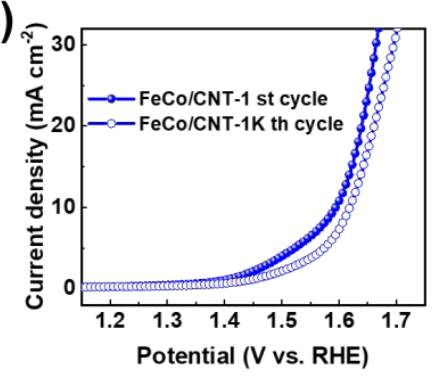

d)

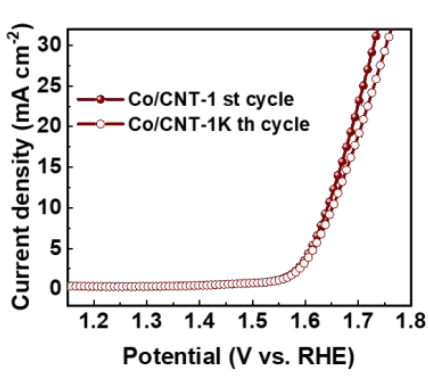

f)

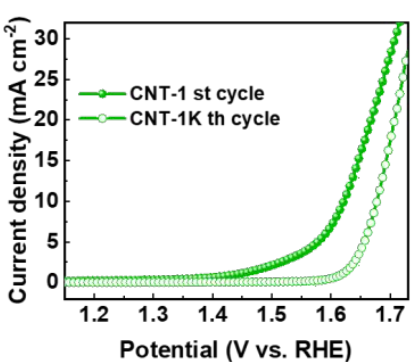

Figure S28. Potential cycling test of $\mathrm{FeCo} / \mathrm{Se}-\mathrm{CNT}$ (a), FeCo/CNT (b), Fe/CNT (c), Co/CNT (d), Se-CNT (e) and CNT (f) in $1 \mathrm{M} \mathrm{KOH}$ media for OER, respectively. 

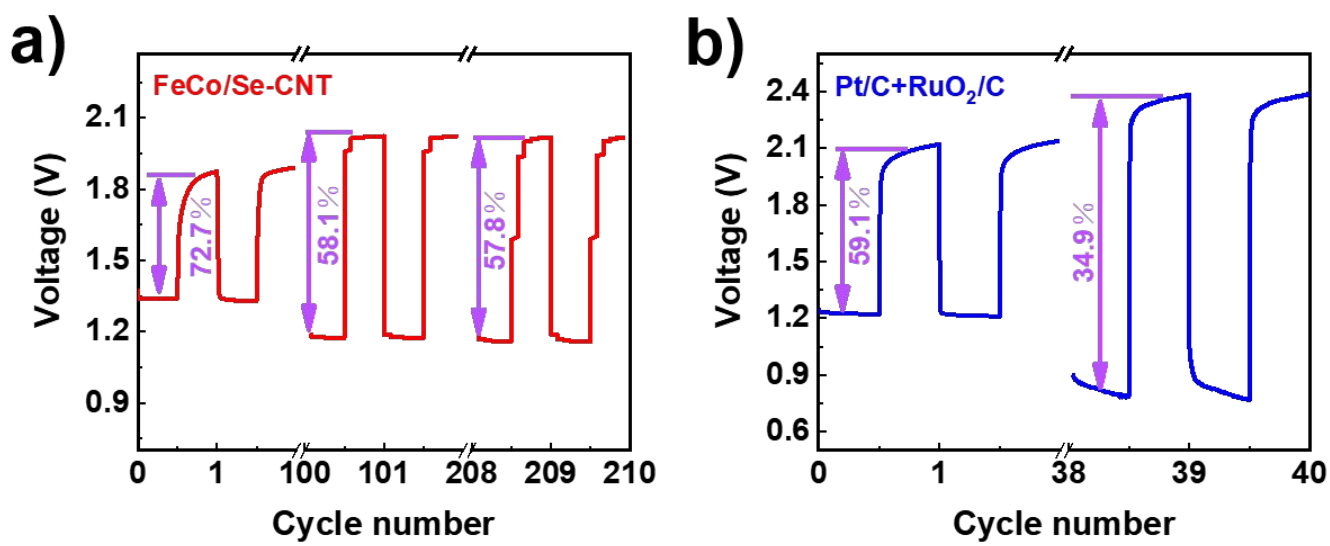

Figure S29. (a) 1st, 101th and 209th discharge-charge curves of FeCo/Se-CNT electrode in liquid Zn-air battery. (b) 1st and 39th discharge-charge curves of $\mathrm{Pt} / \mathrm{C}+\mathrm{RuO}_{2} / \mathrm{C}$ electrode in liquid $\mathrm{Zn}$-air battery.

a)

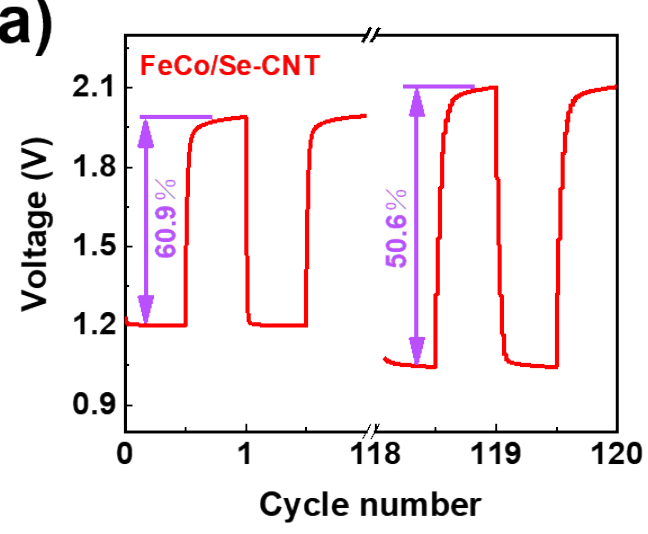

b)

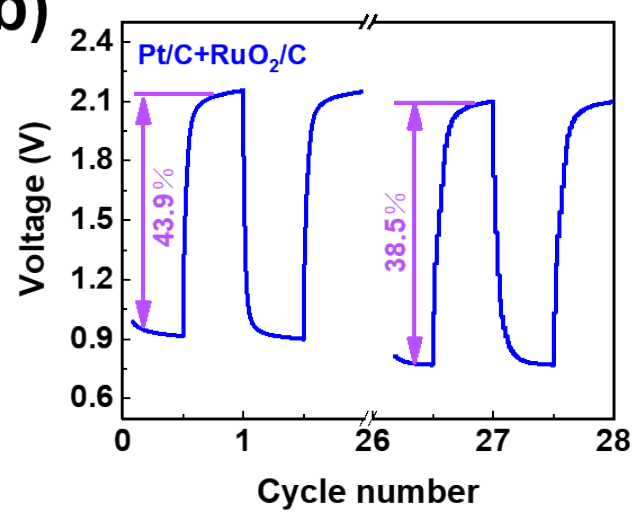

Figure S30. (a) 1st and 119th discharge-charge curves of $\mathrm{FeCo} / \mathrm{Se}-\mathrm{CNT}$ electrode in all-solid-state flexible Zn-air battery. (b) 1st and 27th discharge-charge curves of $\mathrm{Pt} / \mathrm{C}+\mathrm{RuO}_{2} / \mathrm{C}$ electrode in all-solid-state flexible $\mathrm{Zn}$-air battery. 


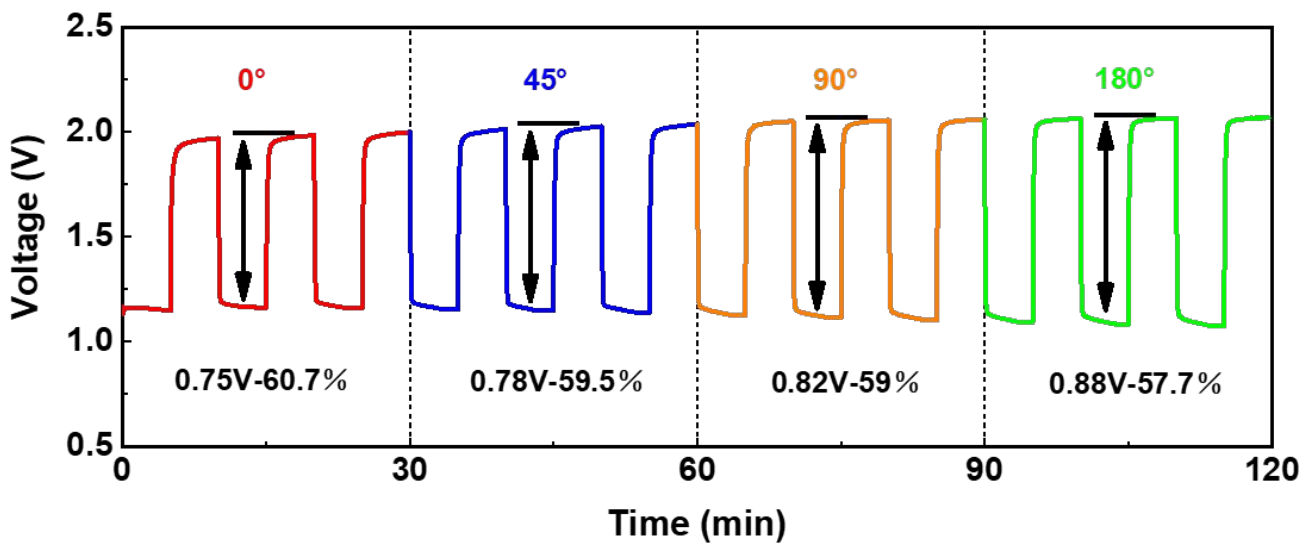

Figure S31. The voltage gap and round-trip efficiency of all-solid-state flexible Znair battery with different bending angles. 
Table S1. Fe, Co and Se content of the FeCo/Se-CNT catalyst.

\begin{tabular}{|l|c|c|c|}
\hline & Fe content & Co content & Se content \\
\hline $\mathrm{FeCo} / \mathrm{Se}-\mathrm{CNT}$ & $20.6 \mathrm{wt} \%$ & $1.96 \mathrm{wt} \%$ & $19.9 \mathrm{wt} \%$ \\
\hline
\end{tabular}

Table S2. EXAFS fitting parameters at the Fe K-edge for various samples

\begin{tabular}{|c|c|c|c|c|c|c|}
\hline Sample & Shell & $\mathbf{N}^{\mathbf{a}}$ & $\mathbf{R}(\AA)$ & $\begin{array}{c}\sigma^{2}\left(\AA^{2 \cdot} \cdot 10^{-3}\right) \\
c\end{array}$ & $\underset{d}{\Delta E_{0}(e V)}$ & $\begin{array}{c}R \text { factor } \\
(\%)\end{array}$ \\
\hline $\mathrm{Fe}$ & $\mathrm{Fe}-\mathrm{Fe}$ & 5.1 & 2.46 & 6.2 & \multirow{2}{*}{0.6} & \multirow{2}{*}{0.4} \\
\hline $\begin{array}{c}(\mathrm{Fec} / \mathrm{Se}- \\
\mathrm{CNT})\end{array}$ & $\mathrm{Fe}-\mathrm{Fe}$ & 4.4 & 2.81 & 10.1 & & \\
\hline \multirow{2}{*}{$\begin{array}{c}\mathrm{Co} \\
(\mathrm{FeCo} / \mathrm{Se}- \\
\mathrm{CNT})\end{array}$} & $\mathrm{Co}-\mathrm{Fe}$ & 7.3 & 2.48 & 8.9 & \multirow{2}{*}{5.9} & \multirow{2}{*}{0.9} \\
\hline & $\mathrm{Co}-\mathrm{Fe}$ & 4.7 & 2.84 & 9.2 & & \\
\hline
\end{tabular}

${ }^{a} N$ : coordination numbers; ${ }^{b} R$ : bond distance; ${ }^{c} \sigma^{2}$ : Debye-Waller factors; ${ }^{d} \Delta E_{0}$ : the inner potential correction. $R$ factor: goodness of fit. $S_{0}^{2}$ was set as 0.88 for $\mathrm{Co} / \mathrm{Fe}-\mathrm{Fe}$, which was obtained from the experimental EXAFS fit of reference Fe foil by fixing $\mathrm{CN}$ as the known crystallographic value and was fixed to all the samples.

Table S3. Summary of performance based on CNTs for ORR in $0.1 \mathrm{M} \mathrm{KOH}$ media and OER in $1 \mathrm{M} \mathrm{KOH}$ media.

\begin{tabular}{|c|c|c|c|c|c|}
\hline Materials & $\begin{array}{c}E_{1 / 2} \\
\text { (V vs. } \\
\text { RHE) }\end{array}$ & $\begin{array}{c}\text { Tafel } \\
\text { slope } \\
\text { (mV dec } \\
\text { 1) }\end{array}$ & $\begin{array}{c}\text { Overpotent } \\
\text { ial } @ J_{10} / \\
m V\end{array}$ & $\begin{array}{c}\text { Tafel } \\
\text { slope } \\
\left(\mathrm{mV} \text { dec }^{-}\right. \\
1)\end{array}$ & Ref \\
\hline FeCo/Se-CNT & 0.9 & 60.9 & 340 & 74.21 & $\begin{array}{l}\text { This } \\
\text { work }\end{array}$ \\
\hline $\mathrm{Fe} @ \mathrm{C}-\mathrm{NG} / \mathrm{NCNTs}$ & 0.84 & 49 & 450 & 163 & 1 \\
\hline
\end{tabular}




\begin{tabular}{|c|c|c|c|c|c|}
\hline $\begin{array}{c}\mathrm{NiCo}_{2} \mathrm{~S}_{4} @ g-\mathrm{C}_{3} \mathrm{~N}_{4^{-}} \\
\mathrm{CNT}\end{array}$ & 0.76 & 74 & 330 & 57 & 2 \\
\hline $\mathrm{Co} @ \mathrm{NC} / \mathrm{CNT}-700$ & 0.81 & 57.36 & 302 & 50.34 & 3 \\
\hline $\mathrm{FeC}$ - $\mathrm{NC} / \mathrm{CNTs}-10$ & 0.79 & 61.5 & 360 & $\mathrm{NG}$ & 4 \\
\hline $\mathrm{Fe} @ \mathrm{~N}-$ & 0.833 & $\mathrm{NG}$ & 350 & 76 & 5 \\
\hline $\mathrm{CNT} / \mathrm{HMCS}$ & & & & & \\
\hline
\end{tabular}

Table S4. Performance comparison of the FeCo/Se-CNT catalyst and some carbonbased single-atom catalysts.

\begin{tabular}{|c|c|c|c|c|c|c|}
\hline & $\begin{array}{c}E_{1 / 2} \\
\text { (V vs. } \\
\text { RHE) }\end{array}$ & $\begin{array}{c}\text { Overpote } \\
\text { ntial } @ \\
J_{10} / \mathrm{mV}\end{array}$ & $\begin{array}{c}\text { Power } \\
\text { density (L) } \\
\left(\mathrm{mW} \mathrm{cm}^{-2}\right)\end{array}$ & $\begin{array}{c}\text { Power } \\
\text { density (S) } \\
\left(\mathrm{mW} \mathrm{cm}^{-2}\right)\end{array}$ & $\begin{array}{l}\text { Stability of } \\
\text { ORR/OER }\end{array}$ & Ref. \\
\hline $\begin{array}{c}\text { FeCo/ } \\
\text { Se- } \\
\text { CNT }\end{array}$ & 0.9 & 340 & 173.4 & 37.5 & $\begin{array}{l}\text { 30k cycles / } \\
\text { 30k cycles }\end{array}$ & $\begin{array}{l}\text { This } \\
\text { Work }\end{array}$ \\
\hline $\begin{array}{c}\mathrm{MnS} \\
\mathrm{AC}\end{array}$ & 0.915 & 350 & 258 & NG & $\begin{array}{l}\text { 20k cycles / } \\
\text { 80k sec. }\end{array}$ & 6 \\
\hline $\begin{array}{c}\mathrm{CoSA} \\
/ \mathrm{N}, \mathrm{S}- \\
\mathrm{HCS}\end{array}$ & 0.85 & 333 & 173.1 & NG & $\begin{array}{l}\text { Decay to } \\
\sim 80 \% / 75 \%\end{array}$ & 7 \\
\hline $\begin{array}{l}\mathrm{Co}- \\
\mathrm{POC}\end{array}$ & 0.83 & 470 & 78 & NG & $\begin{array}{l}\text { Decay to } \\
70 \% / \mathrm{NG}\end{array}$ & 8 \\
\hline $\begin{array}{c}\mathrm{Fe}- \\
\mathrm{NiNC} \\
-50\end{array}$ & 0.78 & 340 & 220 & NG & $\begin{array}{l}5 \mathrm{k} \text { cycles/ } \\
1.5 \mathrm{kcycles}\end{array}$ & 9 \\
\hline $\begin{array}{l}\mathrm{Co}- \\
\mathrm{SAs} @ \\
\mathrm{NC}\end{array}$ & 0.82 & 550 & 105.3 & NG & $\begin{array}{l}\text { Decay to } \\
94.4 \% / \mathrm{NG}\end{array}$ & 10 \\
\hline
\end{tabular}




\begin{tabular}{|c|c|c|c|c|c|c|}
\hline Co & & & & & & \\
$\mathrm{SA} @$ & & & & & & \\
$\mathrm{NCF} /$ & 0.88 & 400 & NG & NG & $97 \% / \mathrm{NG}$ & 11 \\
$\mathrm{CNF}$ & & & & & & \\
\hline $\begin{array}{c}\mathrm{Fe} / \mathrm{N}- \\
\mathrm{G}-\end{array}$ & 0.89 & 370 & 120 & $\mathrm{NG}$ & $10 \mathrm{k}$ cycles $/$ & \\
$\mathrm{SAC}$ & & & & & $2 \mathrm{k}$ cycles & 12 \\
\hline
\end{tabular}

L: Liquid Zn-air battery. S: Solid flexible Zn-air battery. NG = Not Given.

Table S5. Summary of performance based on CNTs for liquid and solid flexible Zn-air batteries $(\mathrm{NG}=$ Not Given.).

\begin{tabular}{|c|c|c|c|c|c|}
\hline \multirow[b]{2}{*}{ Materials } & \multicolumn{2}{|c|}{ Liquid Zn-air battery } & \multicolumn{2}{|c|}{$\begin{array}{c}\text { Solid flexible Zn-air } \\
\text { battery }\end{array}$} & \multirow[b]{2}{*}{ Ref } \\
\hline & $\begin{array}{c}\text { Open } \\
\text { Voltage } \\
\text { (V) }\end{array}$ & $\begin{array}{c}\text { Power } \\
\text { density }(\mathrm{mW} \\
\left.\mathrm{cm}^{-2}\right)\end{array}$ & $\begin{array}{c}\text { Open } \\
\text { Voltage } \\
\text { (V) }\end{array}$ & 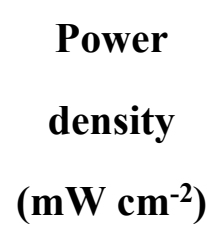 & \\
\hline $\mathrm{FeCo} / \mathrm{Se}-\mathrm{CNT}$ & 1.543 & 173.4 & 1.405 & 37.5 & $\begin{array}{l}\text { This } \\
\text { work }\end{array}$ \\
\hline $\mathrm{Fe} @ \mathrm{C}-\mathrm{NG} / \mathrm{NCNTs}$ & 1.37 & 101.3 & NG & NG & 1 \\
\hline $\begin{array}{c}\mathrm{NiCo}_{2} \mathrm{~S}_{4} @ g-\mathrm{C}_{3} \mathrm{~N}_{4-} \\
\mathrm{CNT}\end{array}$ & 1.45 & 142 & 1.347 & NG & 2 \\
\hline $\mathrm{FeC}_{\mathrm{x}}-\mathrm{NC} / \mathrm{CNT}_{\mathrm{S}}-10$ & 1.47 & 156 & NG & NG & 4 \\
\hline CNT@POF & NG & 237 & 1.39 & 22.3 & 13 \\
\hline $\mathrm{Co} @ \mathrm{~N}-\mathrm{CNT} / \mathrm{rGO}$ & 1.43 & 122 & NG & NG & 14 \\
\hline CoSx/Co-NC-800 & 1.40 & 103 & 1.34 & NG & 15 \\
\hline
\end{tabular}




\section{References}

1. Wang, Q. C.; Lei, Y. P.; Chen, Z. Y.; Wu, N.; Wang, Y. B.; Wang, B.; Wang, Y. D. $\mathrm{Fe} / \mathrm{Fe}_{3} \mathrm{C} @ \mathrm{C}$ nanoparticles encapsulated in N-doped graphene-CNTs framework as an efficient bifunctional oxygen electrocatalyst for robust rechargeable $\mathrm{Zn}$-air batteries. J. Mater. Chem. A. 2018, 6, 516.

2. Han, X. P.; Zhang, W.; Ma, X. Y.; Zhong, C.; Zhao, N. Q.; Hu, W. B.; Deng, Y. D. Identifying the Activation of Bimetallic Sites in $\mathrm{NiCo}_{2} \mathrm{~S}_{4} @ g-\mathrm{C}_{3} \mathrm{~N}_{4}-\mathrm{CNT}$ Hybrid Electrocatalysts for Synergistic Oxygen Reduction and Evolution. Adv. Mater. 2019, 31, 1808281.

3. Yu, D. S.; Ilango, P. R.; Han, S. L.; Ye, M.; Hu, Y. X.; Li, L. L.; Peng, S. J. Int. J. Hydrog. Energy 2019, 44, 32054.

4. Xiao, X.; Li, X. H.; Yu, G. Q.; Wang, J. X.; Yan, G. C.; Wang, Z. X.; Guo, H. J. J. Power Sources 2019, 438, 227019.

5. Liu, J. Y.; Xu, H.; Li, H. P.; Song, Y. H.; Wu, J. J.; Gong, Y. J.; Xu, L.; Yuan, S. Q.; Li, H. M.; Ajayan, P. M. In-situ formation of hierarchical 1D-3D hybridized carbon nanostructure supported nonnoble transition metals for efficient electrocatalysis of oxygen reaction. Appl. Catal. B. 2019, 243, 151.

6. Shang, H. S.; Sun, W. M.; Sui, R.; Pei, J. J.; Zheng, L. R.; Dong, J. C.; Jiang, Z. L.; Zhou, D. N.; Zhuang, Z. B.; Chen, W. X.; Zhang, J. T.; Wang, D. S.; Li, Y. D. Engineering Isolated $\mathrm{Mn}-\mathrm{N}_{2} \mathrm{C}_{2}$ Atomic Interface Sites for Efficient Bifunctional Oxygen Reduction and Evolution Reaction. Nano Lett. 2020, 20, 5443.

7. Zhang, Z. Y.; Zhao, X. X.; Xi, S. B.; Zhang, L. L.; Chen, Z. X.; Zeng, Z. P.; Huang, M.; Yang, H. B.; Liu, B.; Pennycook, S. J.; Chen, P. Atomically Dispersed Cobalt Trifunctional Electrocatalysts with Tailored Coordination Environment for Flexible Rechargeable Zn-Air Battery and Self-Driven Water Splitting. Adv. Energy Mater. 2020, 10, 2002896.

8. Li, B. Q.; Zhao, C. X.; Chen, S. M.; Liu, J. N.; Chen, X.; Song, L.; Zhang, Q. Framework-Porphyrin-Derived Single-Atom Bifunctional Oxygen Electrocatalysts and their Applications in Zn-Air Batteries. Adv. Mater. 2019, 31, 
1900592.

9. Zhu, X. F.; Zhang, D. T.; Chen, C. J.; Zhang, Q. R.; Liu, R. S.; Xia, Z. H.; Dai, L. M.; Amal, R.; Lu, X. Y. Harnessing the Interplay of Fe-Ni Atom Pairs Embedded in Nitrogen-Doped Carbon for Bifunctional Oxygen Electrocatalysis. Nano Energy 2020, $71,104597$.

10. Han, X. P.; Ling, X. F.; Wang, Y.; Ma, T. Y.; Zhong, C.; Hu, W. B.; and Deng, Y. D. GenerationofNanoparticle, Atomic-Cluster,and Single-AtomCobalt Catalysts from Zeolitic Imidazole Frameworks by Spatial Isolationand Their Use in ZincAir Batteries. Angew.Chem. Int.Ed. 2019, 58, 5359.

11. Ji, D. X.; Fan, L.; Li, L. L.; Peng, S. J.; Yu, D. S.; Song, J. N.; Ramakrishna, S.; and Guo, S. J. Atomically Transition Metals on Self-Supported Porous Carbon Flake Arrays as Binder-Free Air Cathode for Wearable Zinc-Air Batteries. Adv. Mater. 2019, 31, 1808267.

12. Xiao, M. L.; Xing, Z.H.; Jin, Z.; Liu, C. P.; Ge, J. J.; Zhu, J. B.; Wang, Y.; Zhao, X.; and Chen, Z. W. Preferentially Engineering FeN4 Edge Sites onto Graphitic Nanosheets for Highly Active and Durable Oxygen Electrocatalysis in Rechargeable Zn-Air Batteries. Adv. Mater. 2020, 32, 2004900.

13. Li, B. Q.; Zhang, S. Y.; Wang, B.; Xia, Z. J.; Tang, C.; Zhang, Q. A porphyrin covalent organic framework cathode for flexible Zn-air batteries. Energy Environ. Sci. 2018, 11, 1723 .

14. Peng, X. M.; Wei, L. C.; Liu, Y. Y.; Cen, T. L.; Ye, Z. F.; Zhu, Z. G.; Ni, Z. T.; Yuan, D. S. Energy Fuels 2020, 34, 8931-8938.

15. Lu, Q.; Yu, J.; Zou, X. H.; Liao, K. M.; Tan, P.; Zhou, W.; Ni, M.; Shao, Z. P. SelfCatalyzed Growth of Co, N-Codoped CNTs on Carbon-Encased $\mathrm{CoS}_{\mathrm{x}}$ Surface: A Noble-Metal-Free Bifunctional Oxygen Electrocatalyst for Flexible Solid Zn-Air Batteries. Adv. Funct. Mater. 2019, 29, 1904481. 